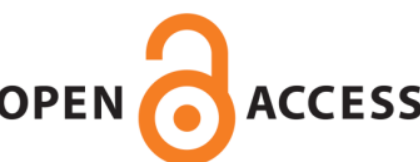

OPEN ACCESS

UWS Academic Portal

\title{
Electrochemical energy storage of silver and silver oxide thin films in an aqueous $\mathrm{NaCl}$ electrolyte
}

Oje, Alex I.; Ogwu, A.A.; Mirzaeian, Mojtaba; Tsendzughul, Nathaniel

Published in:

Journal of Electroanalytical Chemistry

DOI:

10.1016/j.jelechem.2018.10.001

Published: 15/11/2018

Document Version

Peer reviewed version

Link to publication on the UWS Academic Portal

Citation for published version (APA):

Oje, A. I., Ogwu, A. A., Mirzaeian, M., \& Tsendzughul, N. (2018). Electrochemical energy storage of silver and silver oxide thin films in an aqueous $\mathrm{NaCl}$ electrolyte. Journal of Electroanalytical Chemistry, 829, 59-68. https://doi.org/10.1016/j.jelechem.2018.10.001

\section{General rights}

Copyright and moral rights for the publications made accessible in the UWS Academic Portal are retained by the authors and/or other copyright owners and it is a condition of accessing publications that users recognise and abide by the legal requirements associated with these rights.

Take down policy

If you believe that this document breaches copyright please contact pure@uws.ac.uk providing details, and we will remove access to the work immediately and investigate your claim. 


\section{Accepted Manuscript}

Electrochemical energy storage of silver and silver oxide thin films in an aqueous $\mathrm{NaCl}$ electrolyte

Alex I. Oje, A.A. Ogwu, Mojtaba Mirzaeian, Nathaniel Tsendzughul

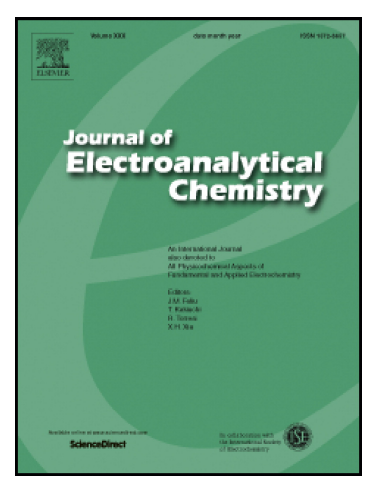

PII:

S1572-6657(18)30661-1

DOI: doi:10.1016/j.jelechem.2018.10.001

Reference: JEAC 12641

To appear in: Journal of Electroanalytical Chemistry

Received date:

9 May 2018

Revised date:

20 September 2018

Accepted date:

1 October 2018

Please cite this article as: Alex I. Oje, A.A. Ogwu, Mojtaba Mirzaeian, Nathaniel Tsendzughul , Electrochemical energy storage of silver and silver oxide thin films in an aqueous $\mathrm{NaCl}$ electrolyte. Jeac (2018), doi:10.1016/j.jelechem.2018.10.001

This is a PDF file of an unedited manuscript that has been accepted for publication. As a service to our customers we are providing this early version of the manuscript. The manuscript will undergo copyediting, typesetting, and review of the resulting proof before it is published in its final form. Please note that during the production process errors may be discovered which could affect the content, and all legal disclaimers that apply to the journal pertain. 


\title{
Electrochemical Energy Storage of Silver And Silver Oxide Thin Films in an Aqueous NaCl Electrolyte.
}

Alex. 1. Oje, A.A. Ogwu, Mojtaba Mirzaeian and Nathaniel Tsendzughul

School of Engineering and Computing, University of the West of Scotland, High Street, Paisley PA1 2BE, UK

Corresponding Author: Alex.1.Oje, E-mail: ifeanyi.oje@uws.ac.uk

\begin{abstract}
:
We present an investigation into the pseudo-capacitive energy storage potential of silver $(\mathrm{Ag})$ and silver oxide $\left(\mathrm{Ag}_{2} \mathrm{O}\right)$ thin film electrode materials prepared by reactive magnetron sputtering. The growth mode and morphology of the prepared films were investigated using the scanning electron microscope (SEM), which reveals columnar growth structure and microporous sites.
\end{abstract}

The stoichiometry and oxidation states of the silver oxide films were monitored with X-ray diffraction analysis (XRD), X-ray photoelectron spectroscopy (XPS) and Fourier transform infra-red spectroscopy (FTIR). The XRD results reveal the nanocrystalline nature of the silver and silver oxide thin films with peak intensities indexed at (111) planes.

Static and dynamic Contact angle measurements were used to probe the penetration of the aqueous $\mathrm{NaCl}$ electrolyte into the pores in the prepared silver and silver oxide films, with surface wettability of all $(\mathrm{Ag})$ and $\left(\mathrm{Ag}_{2} \mathrm{O}\right)$ thin films hydrophilic in nature, which is vital for a good electrochemical performance.

The Faradaic redox reactions, capacitance and the charge discharge of the films when exposed to the $\mathrm{NaCl}$ electrolyte, were monitored with cyclic voltammetry and chronopotentiometry charge-discharge. Results show that Silver and silver oxide 
possess specific capacitance of $240.52 \mathrm{Fg}^{-1}$ and $275.50 \mathrm{Fg}^{-1}$ at $2 \mathrm{mVs}^{-1}$ respectively, which is promising for electrochemical energy storage application.

Keywords: Silver oxide, surface characterization, wettability, charge-discharge, cyclic voltammetry, pseudocapacitor

\section{INTRODUCTION}

Global warming has been an issue for decades. Effort has been made by academia, industrial and governmental agencies to solve this problem, by implementing efficient ways of storing energy. Battery systems have helped for a while in doing this, however, it does not suit applications that require fast charge/discharge time and zero percent oxide emission. Ideally, one device that can fill in the gap left by batteries and other storage devices is a Supercapacitor. Supercapacitors offer cleaner, more efficient and a faster charge/discharge time for all round applications like electric and hybrid vehicles [1], mobile phones, digital cameras, electric tools, uninterruptible power supplies, digital communication devices, off-grid solar energy and regenerative breaking [2]. Supercapacitors store energy by using either charge separation in a Helmholtz double layer (electrochemical double layer capacitor EDLC) [3] or by fast surface redox reactions (pseudocapacitor) [2]. Different materials have been used over the years to process supercapacitors such as carbon, polymers, with carbon based materials being the predominant one, due to their high cycle stability, high specific capacitance, availability and ease of processing. They have a major downside of inability to withstand high temperature application, low specific energy density and limited cell voltage [4]. These problems can be solved by deploying metal oxide based 
electrodes [5] namely ruthenium oxide $\left(\mathrm{RuO}_{2}\right)$ [6], cobalt oxide $\left(\mathrm{CO}_{3} \mathrm{O}_{4}\right)$ [7], nickel oxide (NiO) [8], Indium oxide $\left(\mathrm{In}_{2} \mathrm{O}_{3}\right)$ [9]. Ruthenium oxide been the most performing amongst the transition metal oxide materials for pseudocapacitor application, due to their excellent reversible redox reaction, good thermal stability and broad potential window, with a specific capacitance of $1099 \mathrm{Fg}^{-1}$ reported by Pengfei et al. [10]. The high cost of ruthenium oxide and the low conductivity of other metal oxide materials hinder their wider application. Therefore the need to source for other electrode materials that are cheap and exhibits pseudocapacitance close to ruthenium oxide is paramount. Alternatively, radio frequency magnetron sputtered (RF) silver and silver oxide nano-structure electrodes have been proposed, for supercapacitor application. Studies from Patil et al. and Kalambate et al. [11-12], show that composite silver thin films have been used for supercapacitor applications due to their reasonable surface area and good conductivity. Mojtaba et al. [13] conducted a preliminary investigation on the morphology and wettability of silver oxide thin film electrodes and found that silver oxide has porous morphology and reasonable wettability. The performance of supercapacitor is based on reasonable surface area, porosity and wettability, which are in agreement with findings from Patil et al., Kalambate et al. and Mojtaba et al. [1113]. This makes silver and silver oxide thin films a good candidate for supercapacitor application. The use of nano-structured silver and silver oxide thin film electrodes, combined with the use of aqueous $\mathrm{NaCl}$ electrolyte will have a definite impact on the development of high voltage electrochemical supercapacitors and optimise their energy storage and power capability. Such investigation is therefore timely because of the current interest in high performance supercapacitors. 


\section{EXPERIMENTAL INVESTIGATION}

Silver/Silver oxide thin films were deposited by the radio frequency magnetron sputtering method, on microscope glass slide with dimension $(25.4 \mathrm{~mm} * 76.2 \mathrm{~mm})$, and on 304L stainless steel. A Solid silver target was used as the starting material with high purity argon and oxygen gases as the sputtering and reactive gases. The deposition parameters are as shown in Table 1. Prior to the deposition of silver and silver oxide on the glass and 304 stainless steel substrates, the microscopic glass slide and stainless steel were cleaned with isopropanol and then with deionized water in an ultrasonic bath machine to remove any impurities on the surface.

Table 1: Deposition conditions for Silver and Silver oxide thin films on glass and 304 stainless steel.

\begin{tabular}{|l|l|}
\hline Forward power (W) & $250,300,350$ \\
\hline Oxygen flow rate (sccm) & 10 \\
\hline Argon flow rate (sccm) & 60 \\
\hline Reflective power (W) & $<1$ \\
\hline Temperature & Ambient \\
\hline Deposition time (mins) & 20 \\
\hline
\end{tabular}

The above deposition conditions yield better stoichiometry, morphology, film stability and controllable surface area. A Siemens d5000 x-ray diffractometer model was used 
to characterize the silver and silver oxide thin film stoichiometry and S-4100 scanning electron microscopy (SEM) was used to study the morphology of the prepared Ag and $\mathrm{Ag}_{2} \mathrm{O}$ thin films at $250 \mathrm{~W}, 300 \mathrm{~W}$ and $350 \mathrm{~W}$ deposition power for better morphology control. Further chemical composition of the prepared silver oxide thin films were analyzed using Nicolet iS50 FTIR equipment and Scienta ESCA 300 spectrophotometer, equipped with a monochromatic Al K $\alpha(1486.6 \mathrm{eV})$ x-ray source, for X-ray photoelectron spectroscopy (XPS). Static contact angle, dynamic contact angle (advancing and receding) and contact angle hysteresis measurements were carried out using the CAM 200 goniometer and KSV sigma 700 Tensiometer. The cycle life and capacitive behavior of silver/silver oxide thin film were studied in a $0.5 \mathrm{M} \mathrm{NaCl}$ solution using a PGZ 301 Potentiostat. The PGZ 301 Potentiostat comprises a saturated calomel electrode (SCE), platinum wire and the sample surface, acting as the reference, auxiliary and the working electrodes respectively. The charge discharge and capacitance analysis were investigated using chronopotentiometry charge-discharge and cyclic voltammetry for voltage range of -1000 to $700 \mathrm{mV}$ at $2 \mathrm{mV} / \mathrm{s}$ scan rate for better ion diffusion.

\section{RESULTS AND DISCUSSION.}

\subsection{Structural Studies}

The XRD pattern of the three silver thin films prepared at $250 \mathrm{~W}, 300 \mathrm{~W}$ and 350W using RF magnetron sputtering, are as shown in Figure 1(a), with diffraction peaks indexed at (111) and (200) crystal planes, confirming the nano-crystalline nature of the silver $(\mathrm{Ag})$ thin films deposited at various sputtering powers. These peaks are centered at $38.2^{\circ}$ and $44.48^{\circ}$, with a face centered cubic structure (FCC), an 
attribute of silver thin films without any contamination [14-17]. Moreover, while sputtering power increases, the (111) peak intensity becomes stronger as shown in Figure 1(a). This implies an increase in crystallinity and grain size, with (111) plane having the lowest surface energy $[13,15,18]$. The grain size of the silver film is an important indicator of the crystallization quality, which was calculated using the Scherrer formula.

$$
\mathrm{D}=\frac{0.9 \lambda}{\beta \operatorname{Cos} \theta}
$$

Where $\mathrm{D}$ is the average grain size, $\lambda$ is the wavelength of the incident $\mathrm{X}$-ray (for $\mathrm{Cu}$ $\mathrm{K} \alpha, \lambda=0.154056 \mathrm{~nm}), \beta$ and $\theta$ are the full width at half maximum of the intensity and Bragg angle respectively. Lorentz method was used to analyse the full width at half maximum via magic plot software and Siemens d5000 X-ray diffractometer Eva software. Silver thin films yielded grain size of $27.52 \mathrm{~nm}, 30.12 \mathrm{~nm}$ and $32.88 \mathrm{~nm}$ for Ag deposited at 250W, 300W and 350W respectively similar to Todorov et al. report [15]. The increase in grain sizes with sputtering power signify increase in crystallinity of the silver thin films [15]. 


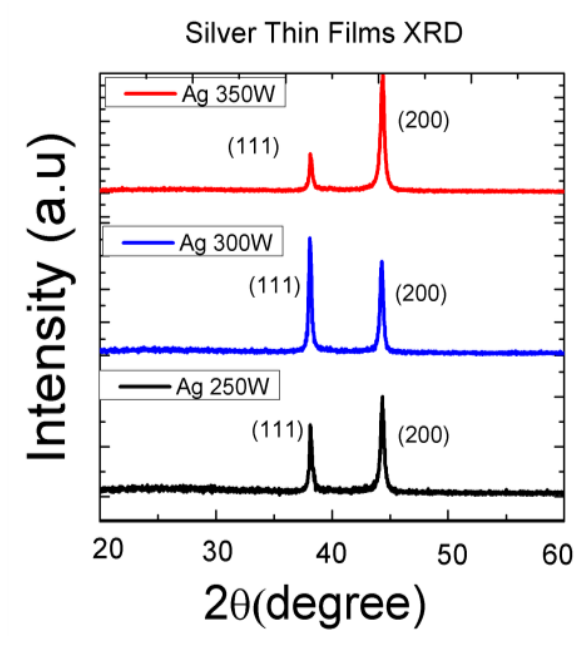

1 (a) Ag XRD at 250, 300W and 350W
Silver Oxide Thin Films XRD

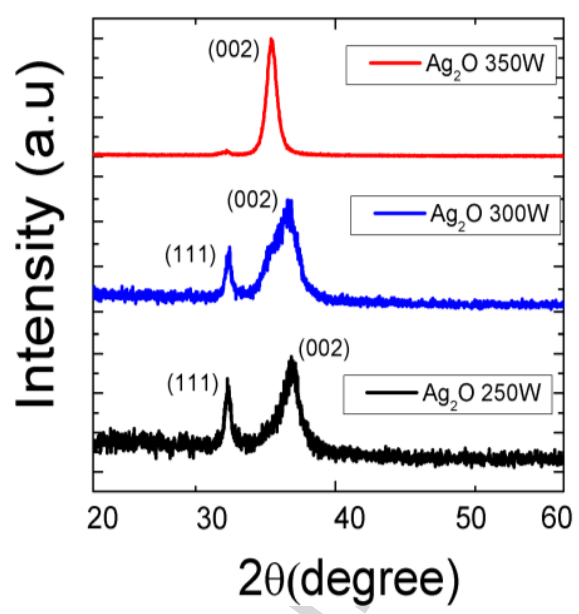

1(b) $\mathrm{Ag}_{\curvearrowright} \mathrm{O}$ XRD at 250, 300W

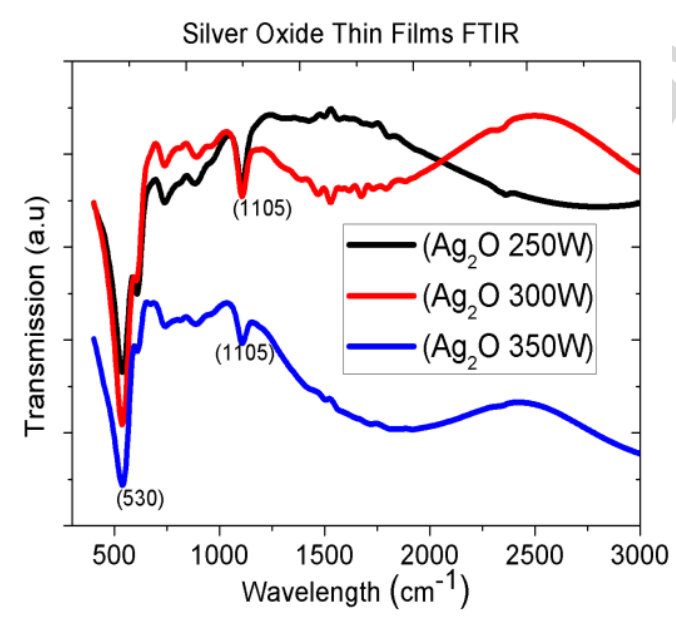

1(c) FTIR of $\operatorname{Ag}_{2} \mathrm{O}$ at 250, 300 and

Figure 1. Shows the XRD and FTIR spectra of thin films Ag and Ag,O

However, silver oxide thin films deposited at 250W, 300W and 350W reveal similar trend to the Ag films, with a strong X-ray diffraction peaks at $32.7^{\circ}$ and $38.2^{\circ}$ as shown in Figure 2(b). These peaks at (111) and (002) planes reflect the cubic structure of silver oxide. There is a progressive increase in the intensity and crystallinity of the silver oxide thin films from $250 \mathrm{~W}$ to $350 \mathrm{~W}$, which were calculated using the Scherrer formula. The silver oxide thin films yielded a grain size of $15.15 \mathrm{~nm}, 17.04 \mathrm{~nm}$ and $20.61 \mathrm{~nm}$ as the sputtering power increased from $250 \mathrm{~W}$ to $350 \mathrm{~W}$. This indicates 
increase in crystallinity of the silver oxide thin films due to the increase in the rate of oxygen difusion into the silver oxide thin film deposited at $350 \mathrm{~W}$ compared to silver oxide thin film deposited at $300 \mathrm{~W}$ and $250 \mathrm{~W}$, resulting in larger grain sizes for silver oxide deposited at 350W [13,19-23]. This is in agreement with the scanning electron microscopy images, where there are more pronounced micropores on silver oxide films sputtered at higher forward power. This finding is very vital for engineering silver oxide based materials, for pseudocapacitor applications.

\subsection{FTIR}

The FTIR result of silver oxide samples prepared at $250 \mathrm{~W}, 300 \mathrm{~W}$ and $350 \mathrm{~W}$ is shown in Figure 1(c), the absorption peaks on the $250 \mathrm{~W}, 300 \mathrm{~W}$, and $350 \mathrm{~W}$ at $1105 \mathrm{~cm}^{-1}$ may be attributed to $\mathrm{O}-\mathrm{H}$ bening vibrations combined with the silver atoms. The absorption band on $530 \mathrm{~cm}^{-1}$ is due to $\mathrm{Ag}-\mathrm{O}$ stretching mode, which corresponds to Ag-O vibration in $\mathrm{Ag}_{2} \mathrm{O}$ [24-26]. FTIR finding indicates the dominance of silver oxide $\mathrm{Ag}_{2} \mathrm{O}$ in the prepared films, which are in agreement with the XRD results in Figure 1(b).

\subsection{XPS}

XPS was employed to investigate the chemical state of the deposited thin films. Figure

2 (a and b) shows the Ag $3 \mathrm{~d}$ and $\mathrm{O}$ 1s spectra, with binding energy observed at 368.3ev consistent with Ag sample [19, 27-30]. The existence of Ag-O bond was also evident in the $\mathrm{O} 1 \mathrm{~s}$ spectra, with peak at $531.8 \mathrm{eV}[19,31-32]$. The $531.8 \mathrm{eV}$ peak originates from the subsurface formation of oxygen, which is a mixture of oxygen and the hydroxyl group. These binding energies are in accordance to standard silver and oxygen binding energies and they support the XRD and FTIR analysis. 


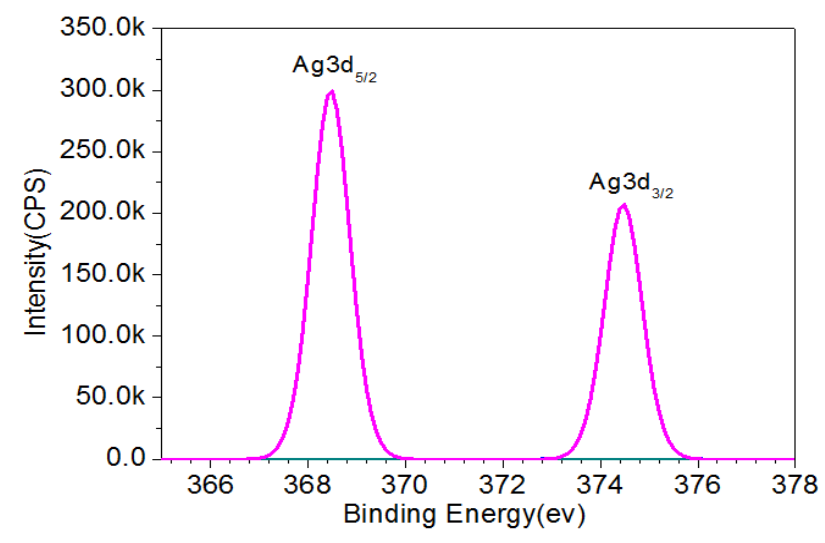

2 (a) $\operatorname{Ag} 3 d$

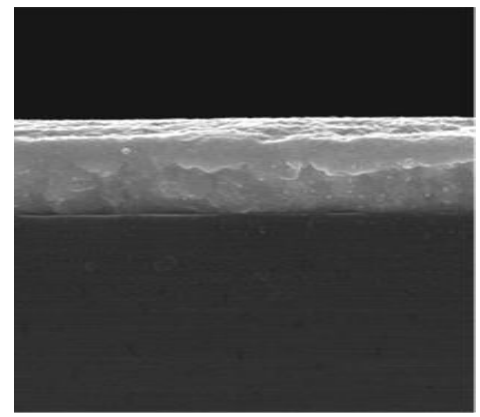

2 (c) Ag SEM

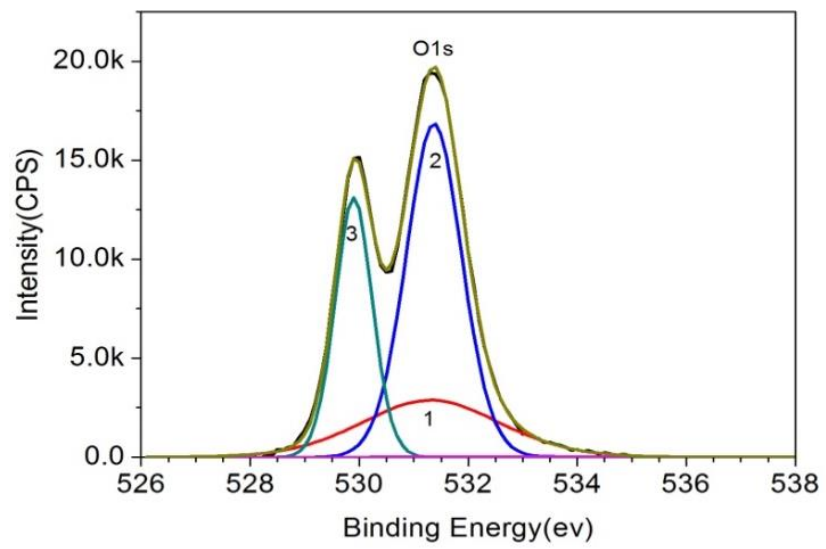

2 (b) $\mathrm{O} 1 \mathrm{~s}$

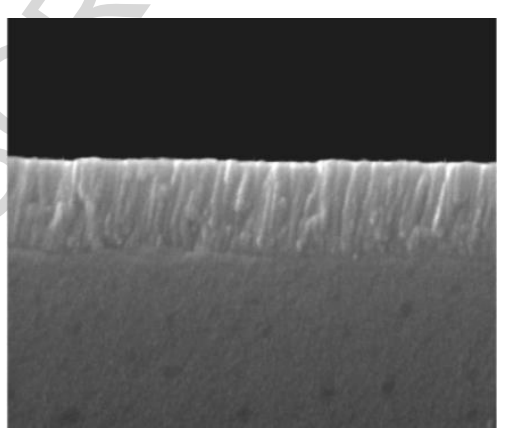

2 (d) $\mathrm{Ag}_{2} \mathrm{O}$ SEM

Figure 2. XPS and cross- sectional view of $\mathrm{Ag}$ and $\mathrm{Ag}_{2} \mathrm{O}$ thin films morphology

\subsection{Morphological Study}

The SEM image in Figure 2 (c) shows a mixture of layer by layer and Volmer-Weber growth mode on silver thin film, while Figure 2(d) shows columnar and porous islands growth mode on the deposited silver oxide thin film. These porous morphologies on the silver oxide thin film facilitate the diffusion of the electrolytes, improves the conductivity, reduces electrodes resistance and accelerates Faradaic 
surface reaction, which are very important for supercapacitor application [33-35]. Wei et al., Staiti et al., Zhang et al. and Keraudy et al. [36-39] reported scanning electron microscopy findings that are similar. The pores on the $\mathrm{Ag}_{2} \mathrm{O}$ thin films increases with power as shown in Figure 3 (d, e, f), which Sun et al. and Min et al. [40-41] reported as due to an increase in the diffusion rate of oxygen molecules, with a high possibility to assemble greater pores at a higher deposition power. The pronounced nano pores on $\mathrm{Ag}_{2} \mathrm{O}$ paves the way for better ions interactions with the electrode/electrolyte interface compared to Ag thin films in Figure $3(\mathrm{a}, \mathrm{b}, \mathrm{c})$. The nano pores are very significant for

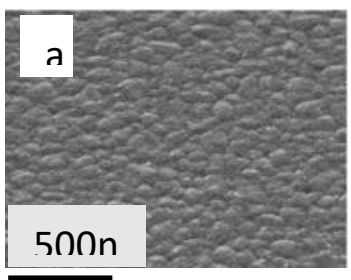

3 (a) Ag SFM at

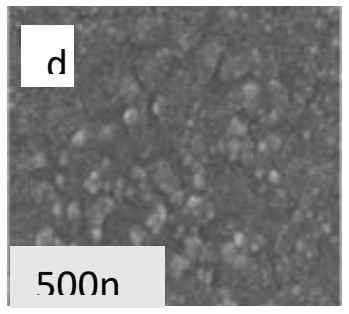

3 (d) $\mathrm{Ag}_{\curvearrowright} \mathrm{O}$ SEM

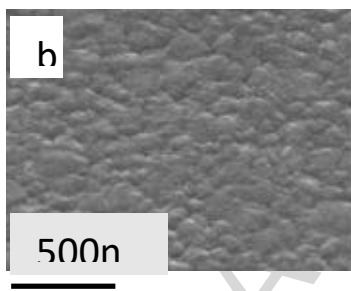

3 (h) Ag SFM at

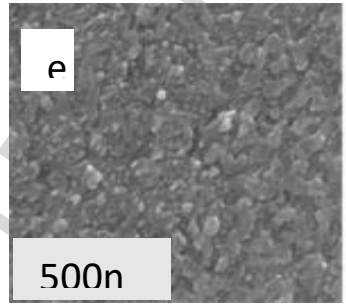

3 (e) $\mathrm{Ag}_{2} \mathrm{O}$ SEM

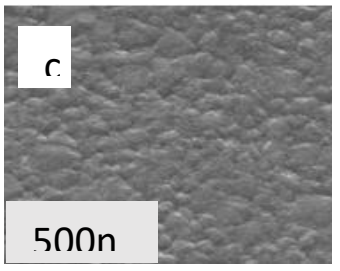

3 (c) Ag SEM at

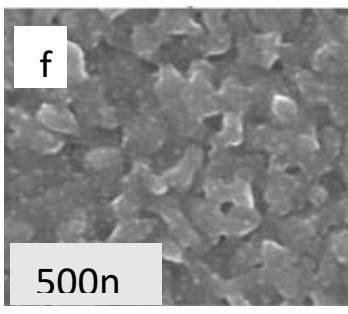

3 (f) $\mathrm{Ag}_{2} \mathrm{O}$ SEM

Figure 3. Top view of $\mathrm{Ag}$ and $\mathrm{Ag}_{2} \mathrm{O}$ thin Films SEM Images

Faradaic surface reaction [42]. 


\subsection{Wettability Test}

Wettability studies were carried out to investigate the interaction of the silver and silver oxide electrodes with electrolytes, which reveal either the hydrophobic or the hydrophilic nature of silver and silver oxide samples [13]. Contact angle measurement gives access to wettability studies, by using sessile drop techniques (static contact angle) on homogeneous surfaces. Static contact angle measurement is governed by young modulus equation shown in equation (2) [43].

$$
\gamma_{s v}=\gamma_{s l}+\gamma_{l v} \operatorname{Cos} \theta
$$

where $\theta, \gamma_{s v}, \gamma_{l v}$ and $\gamma_{s l}$ represent the contact angle, surface energy of the solid, free energy of the liquid and surface energy of the solid-liquid interface, considered as the thermodynamic interfacial energy parameters for solid-vapor, liquid-vapor and solid-liquid respectively. If the wettability is high, contact angle $(\theta)$, will be small and the surface is hydrophilic. On the other hand, if the wettability is low, contact angle $(\theta)$ is high indicating the surface is hydrophobic. Figure 4 (a and b) shows the static contact angle plot of $\mathrm{Ag}$ and $\mathrm{Ag}_{2} \mathrm{O}$ thin films, using KSV Cam 200 goniometer, where water and ethylene glycol are the polar components and diiodomethane the non-polar.

In this present work, the contact angles of the three probing liquid, on the surface of silver and silver oxide thin films are all small $\left(<90^{\circ}\right)$, indicating $\mathrm{Ag}$ and $\mathrm{Ag}_{2} \mathrm{O}$ are hydrophilic in nature [13]. Xingxun et al. proposed that static contact angle tends to decrease as the pore size increases [44], and this stands true with the results obtained 
in this research, where the silver oxide thin film deposited at $350 \mathrm{~W}$ has the smallest contact angle followed by $300 \mathrm{~W}$ and finally $250 \mathrm{~W}$ due to well pronounced pores, which are evident on the SEM micrograph as shown in Figure 3 (d, e, f). The hydrophilic property of the silver and silver oxide thin films is an essential factor for a supercapacitor application, with microspores fundamental to better performance [4546].

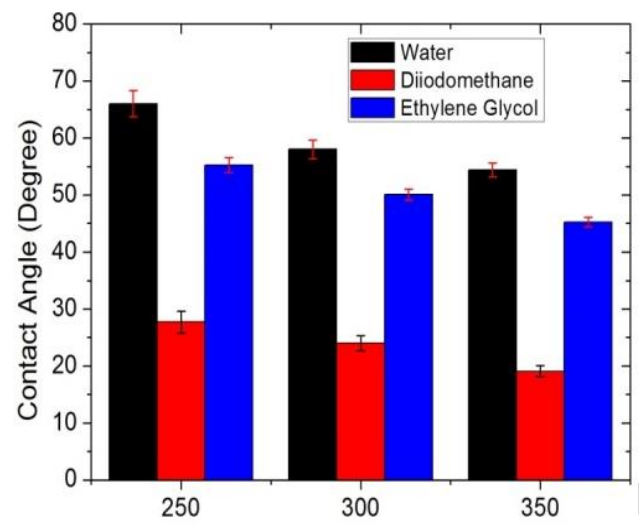

Deposition Power (W)

4(a) Ag static contact angle

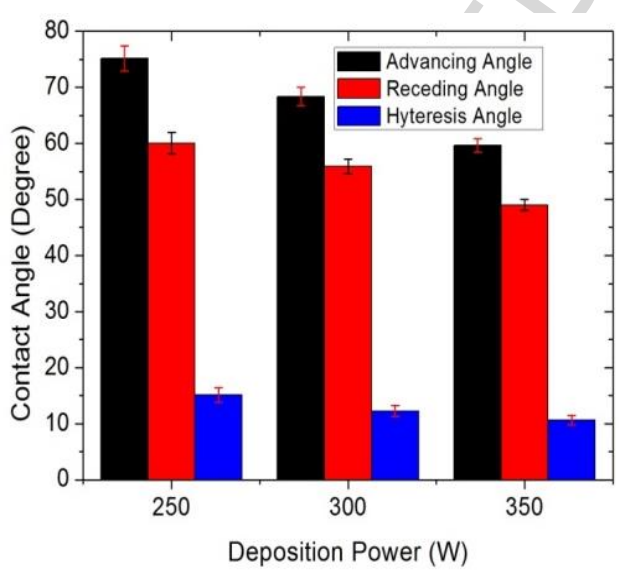

4(c) Ag dynamic contact angle

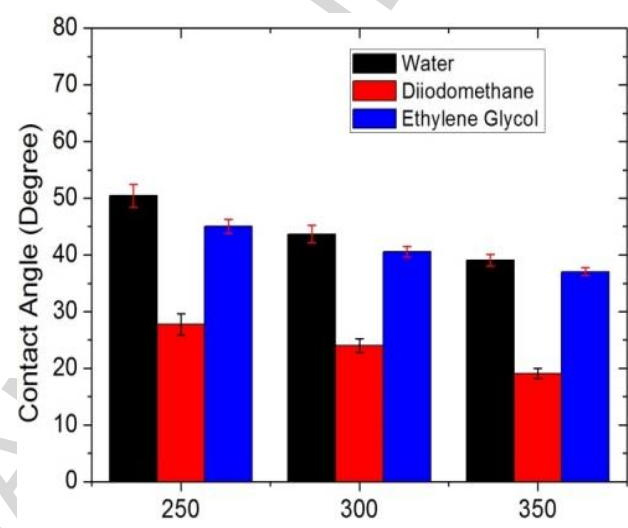

Deposition Power (W)

4 (b) $\mathrm{Ag}_{2} \mathrm{O}$ static contact angle

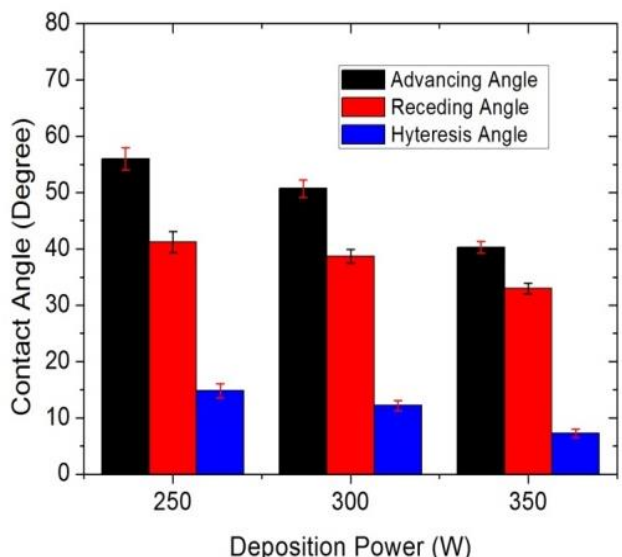

4 (d) $\mathrm{Ag}_{2} \mathrm{O}$ dynamic contact angle

Figure 4. $\mathrm{Ag}$ and $\mathrm{Ag}_{2} \mathrm{O}$ static and dynamic contact angle at deposition power (250W to 
Dynamic tensiometry (KSV sigma 700 tensiometer) measures the changes in the net force on the silver and silver oxide thin film surface during the repeated immersion and emersion into the probing liquids, revealing the wetting properties of the silver and silver oxide prepared films at different sputtering power. Most practical surfaces are non-ideal (heterogeneous in nature) and the measurable contact angle in this situation is referred to apparent contact angle, where the contact angle values fall into more or less wide interval between the advancing and receding angles. Factors contributing to these non-ideality are surface immobility and roughness, which are governed by two main theories Wenzel equation (3) and Cassie-Baxter equation (4) $[43,47-48]$.

$$
\operatorname{Cos} \theta^{*}=r \cos \theta .
$$

Where $\mathrm{r}$ is the roughness factor and $\theta^{*}$ is the contact angle on a smooth surface of the same material and $\theta$ is the absolute contact angle on the heterogenous surface

Cassie-Baxter developed a technique to calculate contact angle on heterogeneous material and on porous materials as shown in equation (4)

$$
\operatorname{Cos} \theta^{*}=f_{1} \cos \theta_{Y}-f_{2}
$$

Where $\theta^{*}=$ apparent contact angle, $\theta_{\mathrm{Y}}=$ equilibrium contact angle and $\mathrm{f}_{1}, \mathrm{f}_{2}$ are the area fractions of the wetted materials. Figure 4(c and d) show the dynamic contact angle measurement of silver and silver oxide thin films from KSV sigma 700 tensiometer 
equipment. The advancing contact angle and the receding contact angles are all less than $90^{\circ}$ (hydrophilicity), with the advancing contact angles on silver and silver oxide thin films similar to the static contact angle in Figure 4(a and b). Sara et al. [49] proposes that the roughness and micro pores make the receding angle to be smaller which is noticeable in in both silver and silver oxide thin films deposited at various sputtering power. The differences in advancing and receding contact angle are smaller in silver oxide thin films compared to silver thin films, giving rise to smaller contact angle hysteresis. This demonstrates better wettability and penetration of the three probing liquids into the pores/columnar structure of the silver oxide thin films microstructure compared to silver thin films [50-51]. Silver oxide thin films deposited at higher forward power, offered excellent electrolyte penetration/interaction, due to the well-pronounced columnar and porous network structure as shown the SEM micrograph in Figure 3 (d, e, and f).

\subsection{Electrochemical impedance spectroscopy (EIS)}

The EIS spectra of silver and silver oxide thin films exposed to the saline solution at alternating sine wave amplitude of $10 \mathrm{mV}$, for the frequency range of $100 \mathrm{mHz}$ to $10 \mathrm{KHz}$ is presented in Figure 5 ( $\mathrm{a}$ and $\mathrm{b}$ ) using Nyquist plot. It is evident from the Nyquist plot in Figure 5, that silver and silver oxide thin films deposited at 250W, $300 \mathrm{~W}$ and $350 \mathrm{~W}$, show capacitive behaviour in the frequency range of $100 \mathrm{mHz}$ and acts as a resistor at high frequency of $10 \mathrm{KHz}$. Yuksel et al. [52], reported that the absence of semicircle on the Nyquist plot of silver and silver oxide thin film is due to the high conductivity of the silver and silver oxide thin films in high frequency region. The Nyquist plot displays intercalation process, namely ion diffusion in the silver 
oxide thin film electrode $\left(\mathrm{Ag}_{2} \mathrm{O} 350 \mathrm{~W}\right)$, symbolized by the $45^{\circ}$ spectra line to the $\mathrm{Zi}$ axis. This is a representation of electrode/electrolyte interface interaction and capacitive behaviour of the deposited silver oxide thin films [53-54]. Braam et al. [55], attributes the $45^{\circ}$ spectra line to the $\mathrm{Zi}$ axis to the Warburg impedance diffusion of the hydroxide ion and oxidized species. There is an obvious deviation of silver thin films deposited at 250W, 300W and 350W as shown in Figure 5a from the $45^{\circ}$ spectra line to the $Z^{\prime}$ axis. These deviations, Criado et al. [56] associates to non-homogeneity of the silver thin films coating and the reflective boundary condition at the electrode. Furthermore, Z-view software was used to fit the equivalent circuit model of the silver and silver oxide thin films in saline solution. This gives an indication of the solution resistance $\left(R_{s}\right)$ and polarization resistance $\left(R_{p}\right)$. The equivalent circuit model yielded $\left(\mathrm{R}_{\mathrm{p}}\right)$ of $21 \Omega, 9 \Omega, 6 \Omega$ for silver thin films sputtered at $250 \mathrm{~W}, 300 \mathrm{~W}, 350 \mathrm{~W}$ and $10 \Omega$, $8 \Omega$ and $4 \Omega$ for silver oxide thin films prepared at $250 \mathrm{~W}, 300 \mathrm{~W}$ and $350 \mathrm{~W}$ respectively. Silver oxide thin film deposited at $350 \mathrm{~W} 10 \mathrm{sccm}$, show smallest real impedance, an indication that more energy is stored on silver oxide thin film sputtered at $350 \mathrm{~W} 10 \mathrm{sccm}$. 


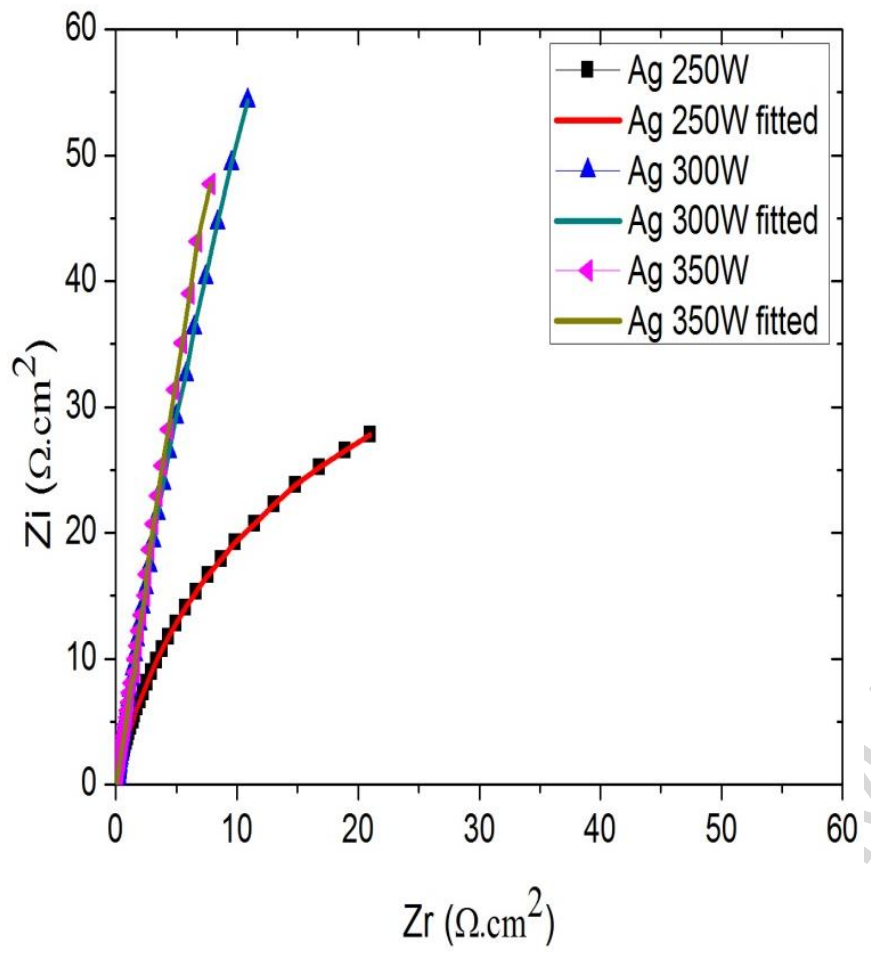

5 (a) Nyquist plot of Ag thin films

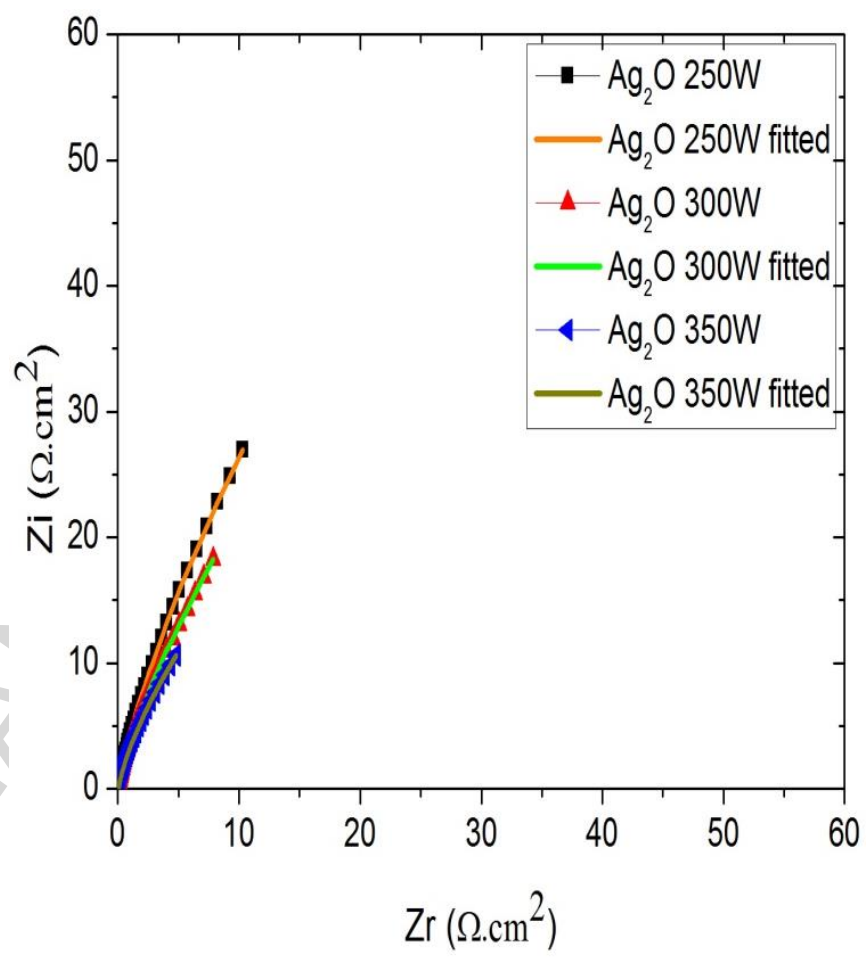

5 (b) Nyquist plot of $\mathrm{Ag}_{2} \mathrm{O}$ thin films

\section{Figure 5: EIS spectra of $\mathrm{Ag}$ and $\mathrm{Ag}_{2} \mathrm{O}$ thin films using Nyquist plot}

\subsection{Cyclic voltammetry (CV)}

Cyclic voltammetry (CV) curves provide the avenue for evaluating the capacitance of a supercapacitor. CV curves show two different regions, anodic (positive current values) and cathodic (negative current values) where the redox reactions occur respectively. Several important parameters characterize cyclic voltammetry, such as peak currents and peak potentials [57]. Yin et al. [58] stated that the specific 
capacitance from the voltammetry curve can be evaluated using the following equation

$$
C s=\frac{I}{m v(V a-V c)} \int_{V a}^{V c} I(V) d V
$$

Where $\mathrm{C}_{\mathrm{S}}$ is the specific capacitance in $\mathrm{F} / \mathrm{g}, \mathrm{m}$ indicates the mass of the active electrode material, $\mathrm{I}$ the responses current, $\mathrm{v}$ is the scan rate and $\Delta \mathrm{V}$ is the potential range for anodic $\left(\mathrm{V}_{\mathrm{a}}\right)$ and cathodic voltages $\left(\mathrm{V}_{\mathrm{c}}\right)$. The supercapacitive performance of silver thin films prepared at different deposition powers of $250 \mathrm{~W}, 300 \mathrm{~W}$ and $350 \mathrm{~W}$ were characterized using cyclic voltammetric techniques. Figure 6 shows the three silver thin film electrodes $\mathrm{CV}$, with redox peaks both on the anodic and cathodic sides, due to faradaic reactions. This implies that the capacitance associated with silver thin films electrodes are pesudocapacitive in nature. Dar et al. [59] reported that the peaks at the cathodic and anodic sides of the CV are due to the diffusion, interfacial kinetics reaction and ion transfers at efficient rates, meaning anions are exchanged between the electrode and electrolytes during redox reaction as shown in equation (6 and 7) [59-61]. The CV of silver thin films deposited at different sputtering power observed in Figure 6 are similar to the ones observed by [62-63], with the oxidation peak of the three silver thin films located at $+0.4 \mathrm{~V}$. The appearance of peaks at the anodic side of $\mathrm{Ag}$ thin films is due to the oxidation of $\mathrm{Ag}$ in the presence of the Chloride ion [64-65] as shown in equation (6),

$$
2 \mathrm{Ag}+2 \mathrm{OH}^{-} \longrightarrow \mathrm{Ag}_{2} \mathrm{O}+\mathrm{H}_{2} \mathrm{O}+2 \mathrm{e}^{-}
$$


A reverse process is seen at the cathodic side of the silver thin films of 250, 300 and $350 \mathrm{~W}$ with peaks located at $-0.5 \mathrm{~V}$, due to the reduction of $\mathrm{Ag}_{2} \mathrm{O}$ to $\mathrm{Ag}$ [64].

$$
\mathrm{Ag}_{2} \mathrm{O}+\mathrm{H}_{2} \mathrm{O}+2 \mathrm{e}^{-} \longrightarrow 2 \mathrm{Ag}+2 \mathrm{OH}^{-}
$$

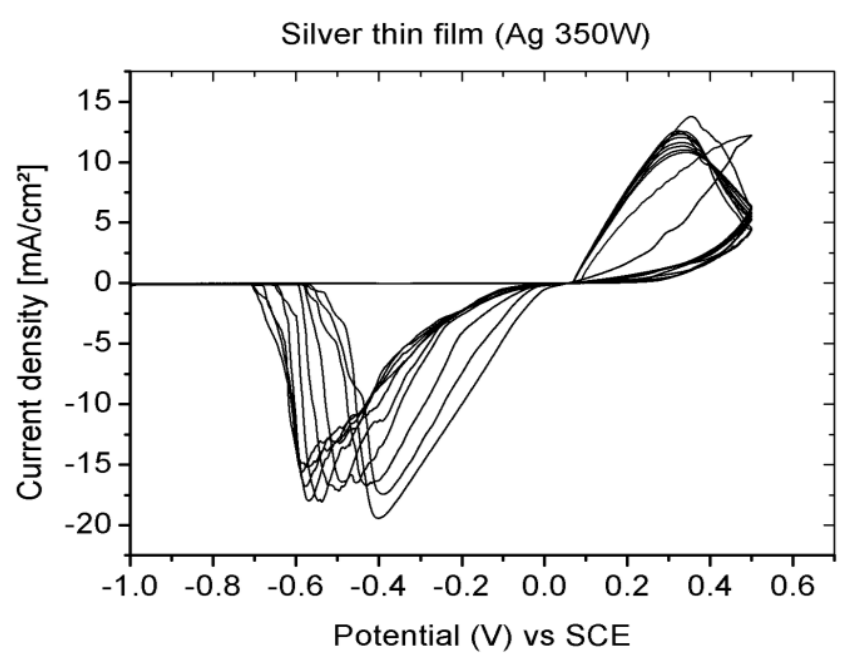

6 (a) CV of Ag thin film at 350W

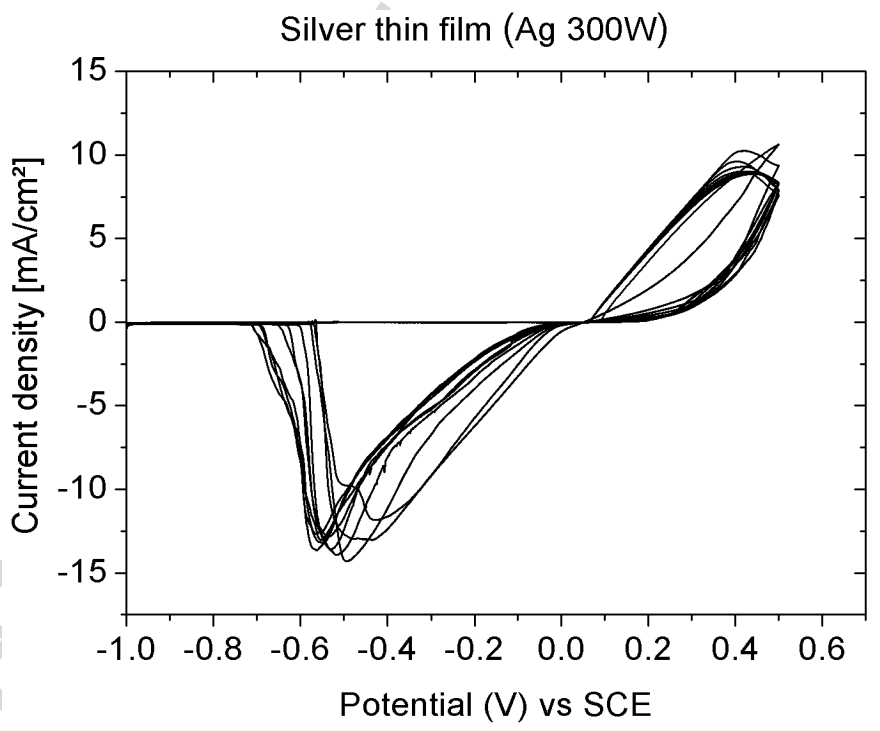

6 (b) CV of Ag thin film at $300 \mathrm{~W}$

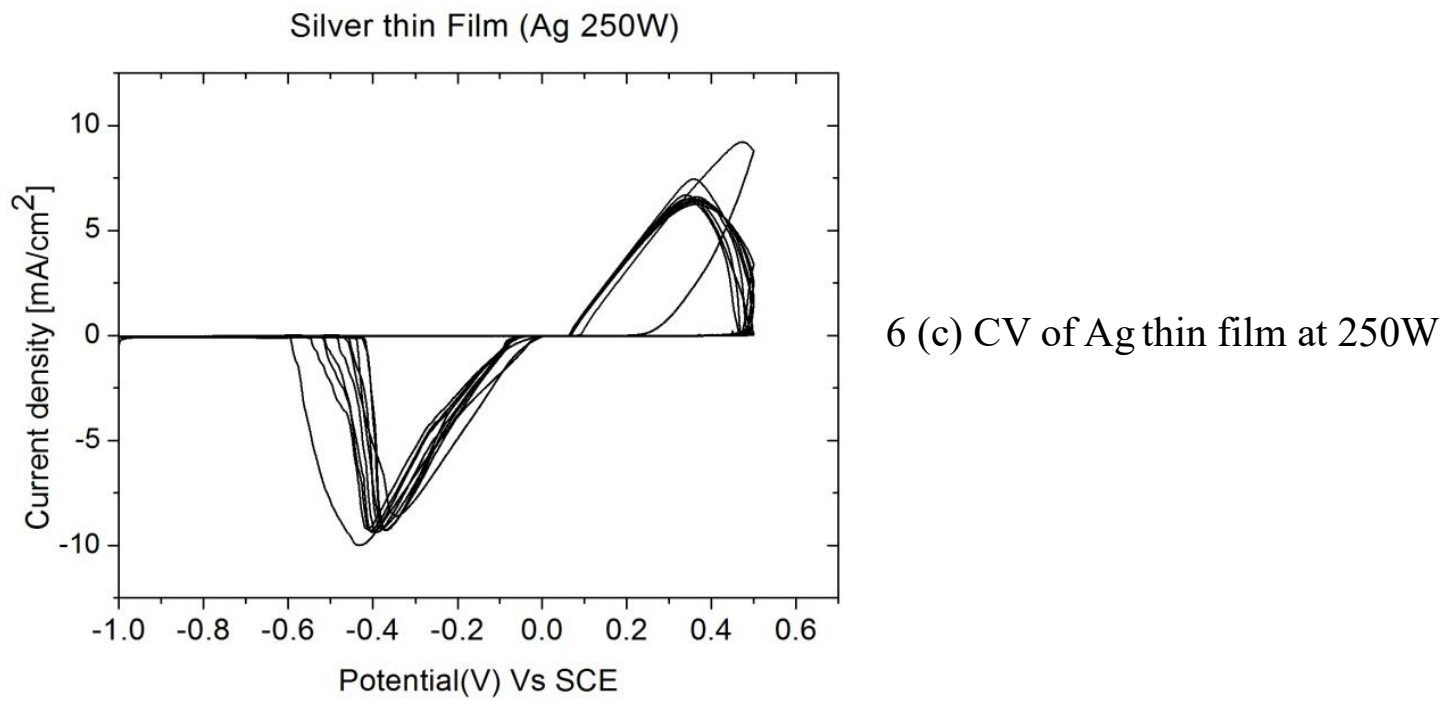

Figure 6. Cyclic voltammetry (CV) of Ag thin films.

The CV of silver oxide thin films deposited at different forward power at oxygen flow rate of $10 \mathrm{sccm}$ are as shown in Figure 7 , with anodic peaks located at $+0.4 \mathrm{~V}$ for all the 
samples of silver oxide thin films [62-63]. The appearance of peaks at the anodic side of $\mathrm{Ag}_{2} \mathrm{O}$ thin film is due to the oxidation of $\mathrm{Ag}_{2} \mathrm{O}$ in the presence of the Chloride ion [64] as shown in equation (8), with the anodic current observed, which Zhang et al. [62] attributed to chemisorption process, rapid oxide nucleation and ion migration into the microspores revealed in the SEM analysis [65].

$$
\mathrm{Ag}_{2} \mathrm{O}+2 \mathrm{OH}^{-} \longrightarrow 2 \mathrm{AgO}+\mathrm{H}_{2} \mathrm{O}+2 \mathrm{e}^{-}
$$

A reverse process is seen at the cathodic side of the silver oxide thin films deposited at 250,300 and $350 \mathrm{~W}$ at $10 \mathrm{sccm}$ oxygen with peaks located at $-0.5 \mathrm{~V}$, due to the reduction of $\mathrm{Ag}_{2} \mathrm{O}$ [64-65].

$$
2 \mathrm{AgO}+\mathrm{H}_{2} \mathrm{O}+2 \mathrm{e}^{-} \longrightarrow \mathrm{Ag}_{2} \mathrm{O}+2 \mathrm{OH}^{-}
$$

The specific cpacitance of silver oxide thin films deposited at 250W, 300W and $350 \mathrm{~W}$ were calculated using equation (5) and results shown in table 2 . Peak current at each of the voltage levels of the anodic and cathodic sides of the silver and silver oxide thin films, indicate pseudocapacitance behaviour. This symbolise effective utilization of active electrode material by electrolyte ions during electrochemical reaction. More specific capacitance is generated by silver oxide thin films deposited at $350 \mathrm{~W}, 300 \mathrm{~W}$, and $250 \mathrm{~W}$ compared to silver thin at $350 \mathrm{~W}, 300 \mathrm{~W}, 250 \mathrm{~W}$ as shown in table 2, due to the formation of well-interconnected pores, which pave the way for better penetration and interaction of the silver oxide thin film electrodes with the electrolyte, yielding better electrochemical performance [65]. The higher capacitance values obtained for silver oxide thin films electrode is attributed to presence of more 
pronounced pores, colunmar growth structure, which makes way for better electrolyte pentration.

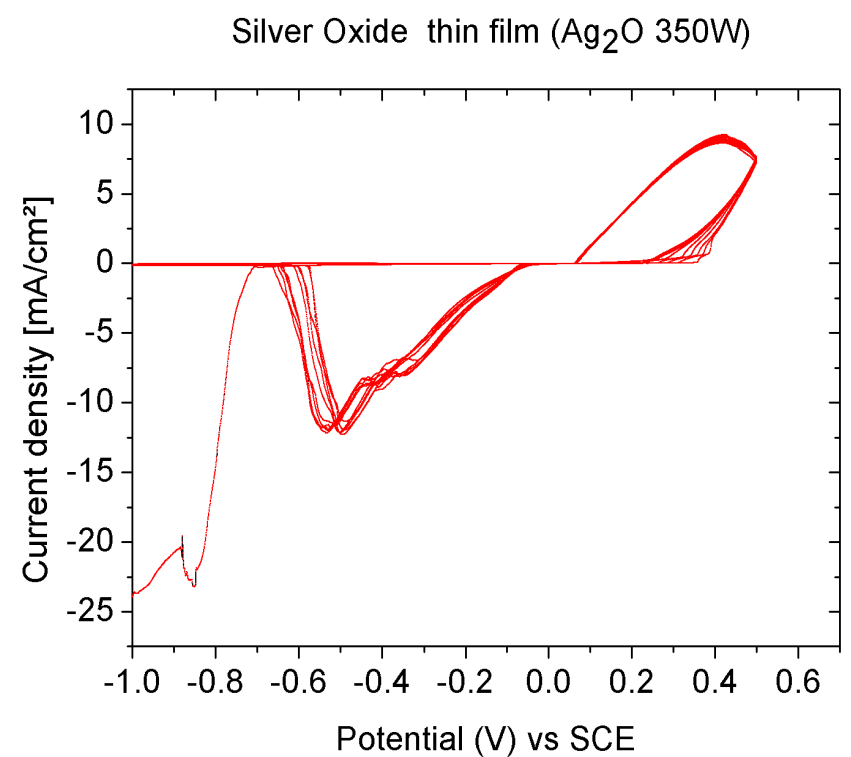

7 (a) $\mathrm{CV}$ of $\mathrm{Ag}_{2} \mathrm{O}$ thin film at $350 \mathrm{~W}$

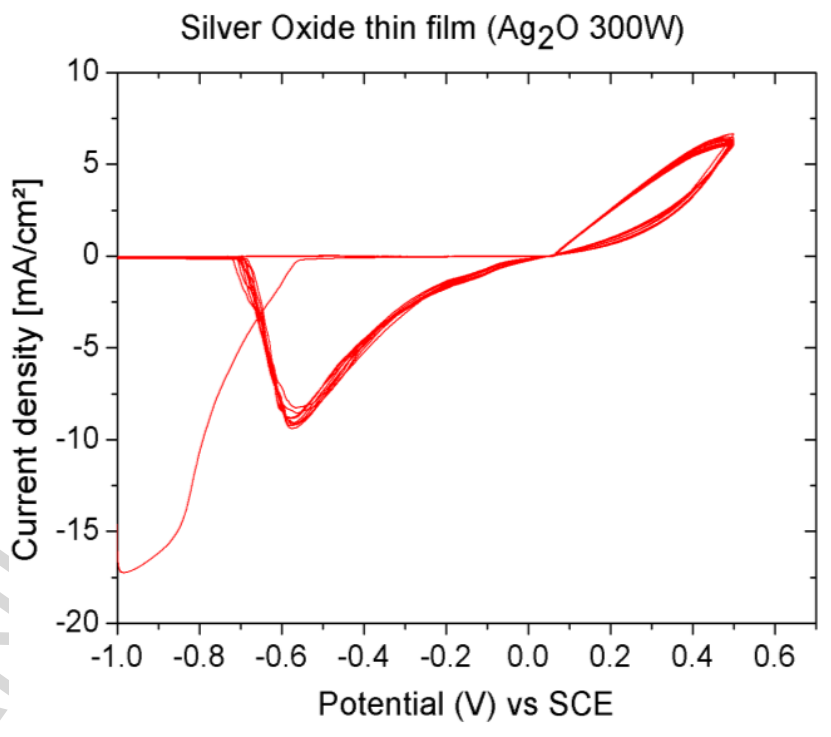

7 (b) $\mathrm{CV}$ of $\mathrm{Ag}_{2} \mathrm{O}$ thin film at $300 \mathrm{~W}$

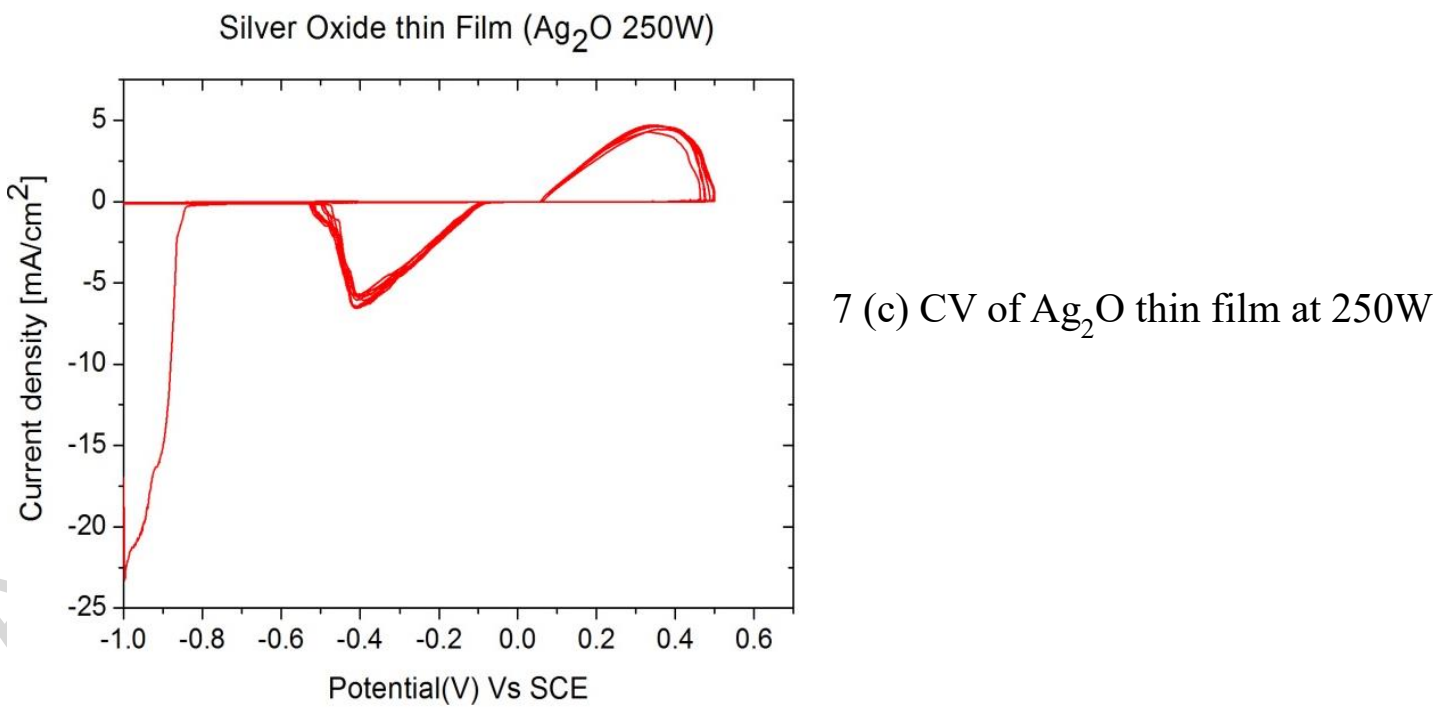

Figure 7. Cyclic voltammetry (CV) of $\operatorname{Ag}_{2} \mathrm{O}$ thin films.

The specific capacitance of the three silver thin films were calculated using equation

(5), with specific capacitance decreasing with sputtering power. This is ascribed to 
better wettability and diffusion of ions at higher sputtering power, inline with the SEM micrograph and contact angle measurement.

Table 2. Specific Capacitance of Silver and Silver Oxides at different Sputtering Powers

\begin{tabular}{|l|l|l|}
\hline Sample/ Scan rate $(2 \mathrm{mV} / \mathrm{s})$ & Deposition Power $(\mathrm{W})$ & Specific capacitance $(\mathrm{F} / \mathrm{g})$ \\
\hline $\mathrm{Ag}$ & 250 & 207.45 \\
\hline $\mathrm{Ag}$ & 300 & 230.68 \\
\hline $\mathrm{Ag}$ & 350 & 240.52 \\
\hline $\mathrm{Ag}_{2} \mathrm{O}$ & & 210.21 \\
\hline $\mathrm{Ag}_{2} \mathrm{O}$ & 250 & 232.34 \\
\hline $\mathrm{Ag}_{2} \mathrm{O}$ & 300 & 275.50 \\
\hline
\end{tabular}

To further get more information on the electrochemical stability of the sputtered silver and silver oxide thin films, charge-discharge cycling test was carried out at current density of $1 \mathrm{Ag}^{-1}$ for ten thousand cycles as shown in Figure 8. The specific capacitance retention of silver and silver oxide thins decreased after 7800 cycles to around $7 \%$. This gives rise to specific capacitance retention of $93 \%$, an indication of a reasonable cyclic stability of silver and silver oxide thin films [52-53]. 


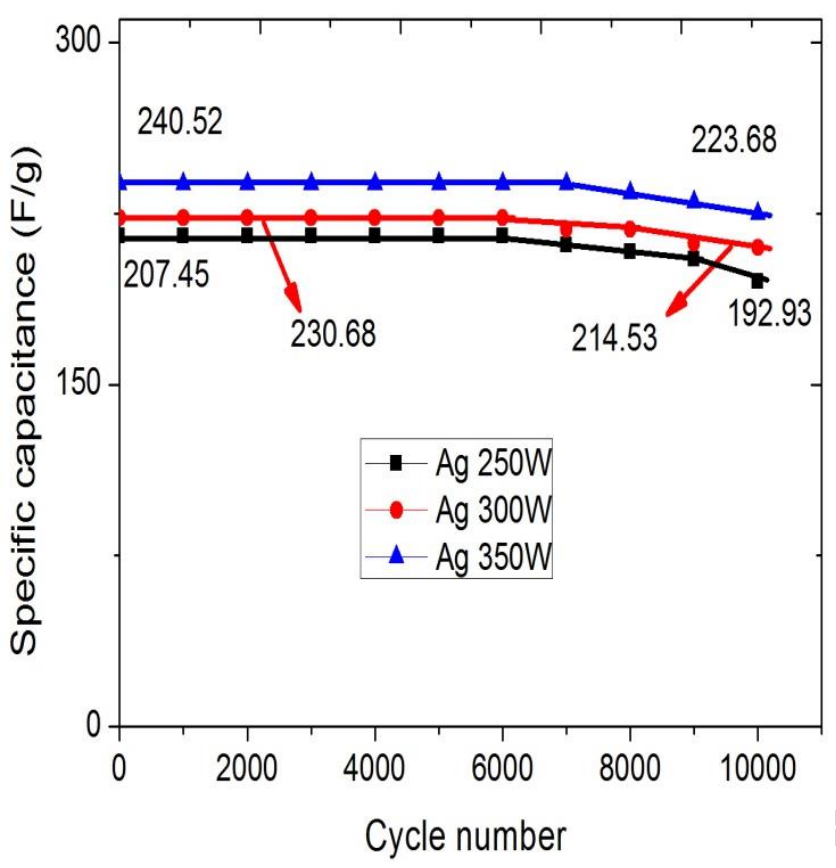

8 (a) Ag thin films

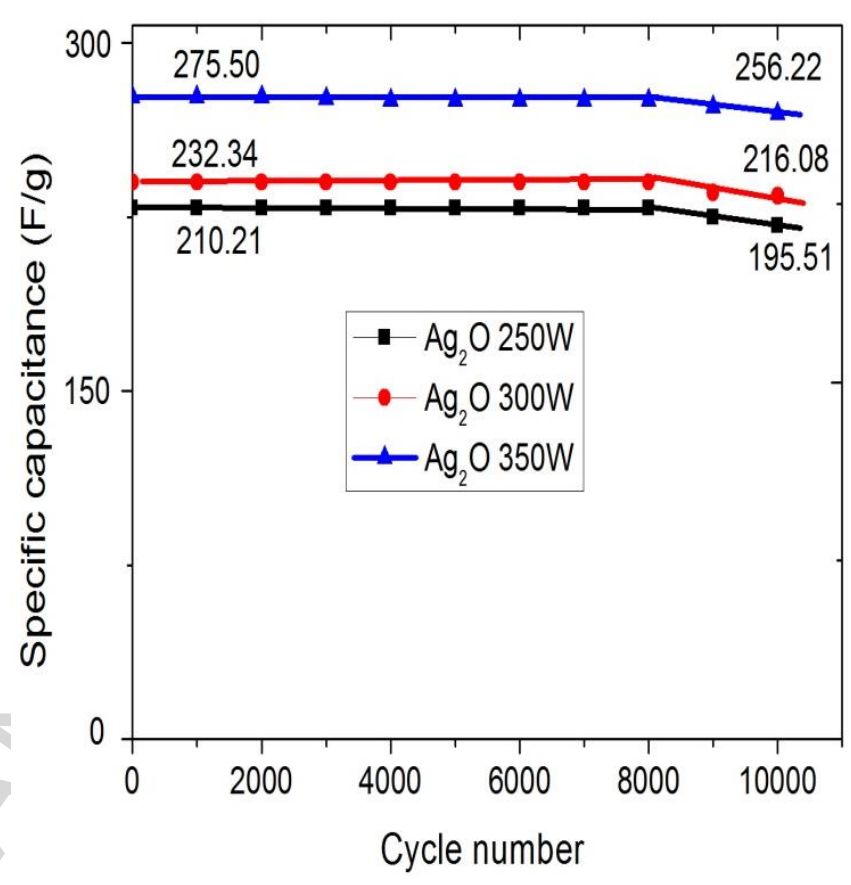

8 (b) $\mathrm{Ag}_{2} \mathrm{O}$ thin films

Figure 8. Capacitance cyclic test of $\mathrm{Ag}$ and $\mathrm{Ag}_{2} \mathrm{O}$ thin films

\subsection{Charge -discharge}

The capacitive behaviour of silver and silver oxide thin films were examined by chronopotentiometry charge-discharge for voltage range of -1000 to $700 \mathrm{mV}$ as shown in Figure 8 and 9. The pseudocapacitance of the deposited silver and silver oxide thin films were calculated using equation (10).

$$
C=\frac{I}{m(d E / d t)}
$$


Where $[(\mathrm{dE} / \mathrm{dt})]$ is the slope of the charge discharge curves, m mass of the Ag and $\mathrm{Ag}_{2} \mathrm{O}$ thin films, $\mathrm{I}=$ current, $\mathrm{C}$ is the specific capacitance in $\mathrm{F} / \mathrm{g}$

The charge-discharge curves in Figure 9 for the silver thin films prepared at 250W, 300W and 350W appear to be symmetrical, which is an indication that the capacitance behaviour is due to faradaic reaction. This is in agreement with the results obtained for silver CV measurements shown in Figure 6, which reveals redox peaks, as a result of the oxidation (charging curve) and reduction (dis-charge curve) reaction at the interface of the silver thin film electrodes and the eletrolytes as shown in equation (6) and (7). Berchman et.al [66] proposed that the sudden rise in the charging cycle voltage of the three silver thin film electrodes is due to the electrolysis of water. Using equation (10), the specific capacitance of silver thin film electrodes were calculated, yielding Specific capacitance of $150.25,170.12$ and $200.41 \mathrm{~F} / \mathrm{g}$ for silver films prepared at sputtering power of $250 \mathrm{~W}, 300 \mathrm{~W}$ and $350 \mathrm{~W}$. The decrease in specific capacitance as sputtering power decreased is due to the less migration of ions to the active areas of the thin film silver electrodes materials, resulting in lower charge storage and hence a low specific capacitance [67-68]. This is inline with the contact angle and morphological analysis, where silver thin film electrodes prepared at higher power, has better wettability and pronounced pores in the microstructural arrangement. Furthermore, the charge-discharge curves of the silver oxide thin films in Figure 10, prepared at 250W, 300W and 350W appear to be mirror images of each other, which confirms that the capacitance behaviour is mainly due to faradaic reaction. This is in agreement with the silver oxide $\mathrm{CV}$ in Figure 7 which reveals redox peaks, as a result of the oxidation (charging curve) and reduction (dis-charge 
curve) reaction, at the interface of the three silver oxide thin film electrodes and the eletrolytes, as shown in equation (8) and (9). Charge storage is due to the surface adsorption of cations and the intercalation/de-intercalation of ions into the silver oxide thin film electrodes, during oxidation and reduction cycle, which Radhamani et.al proposed [69].Using equation (10), the specific capacitance of silver oxide thin film electrodes were calculated, resulting in Specific capacitance of 168.02, 200.10 and 235.01F/g for silver oxide film prepared at deposition power of $250 \mathrm{~W}, 300 \mathrm{~W}$ and 350W. Morphology and wettability been some of the key parameters for a supercapacitor to retain higher specific capacitance. Silver oxide thin film prepared at 350W demonstrated this, giving lower contact angle and well pronounced columnar growth structure, leading to better ion migration, diffusion and higher specific capacitance, compared to the rest of thin films prepared at different deposition power [64, 69-70]. 
Silver Thin Film (Ag 350W)

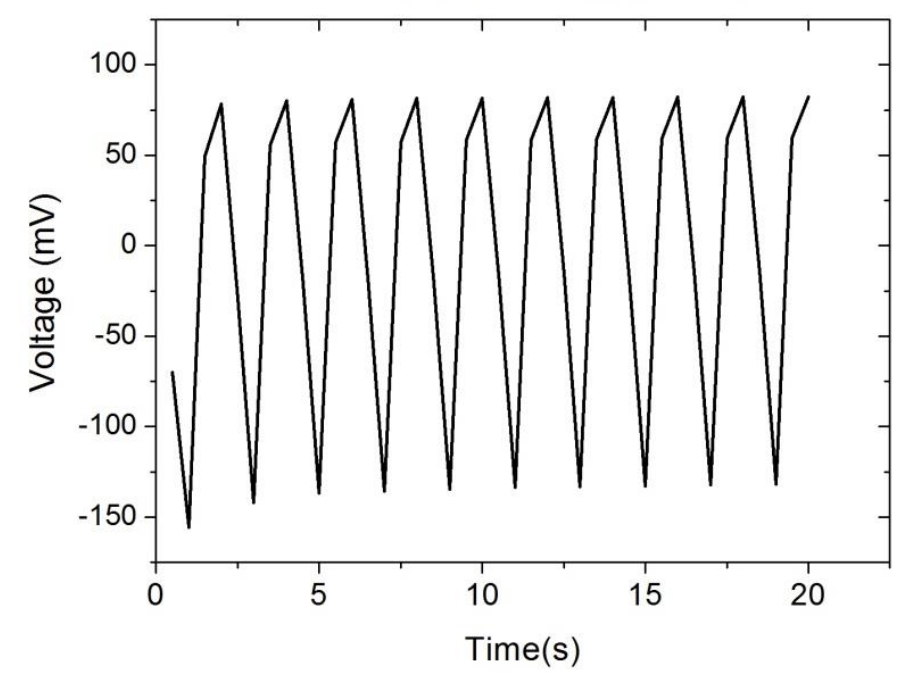

9 (a) Ag at 350W

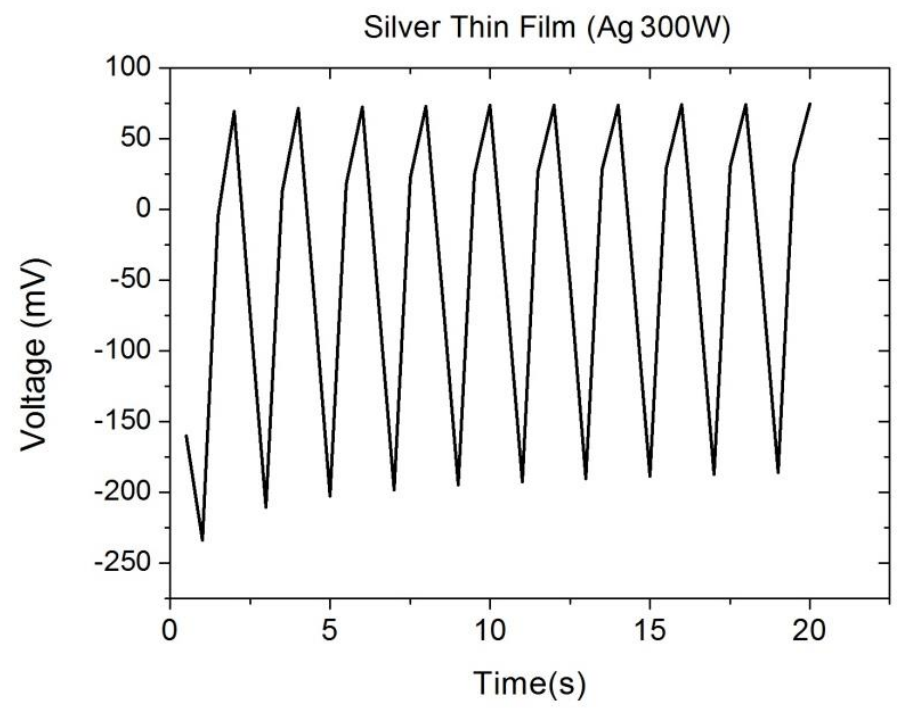

9 (b) Ag at 300W

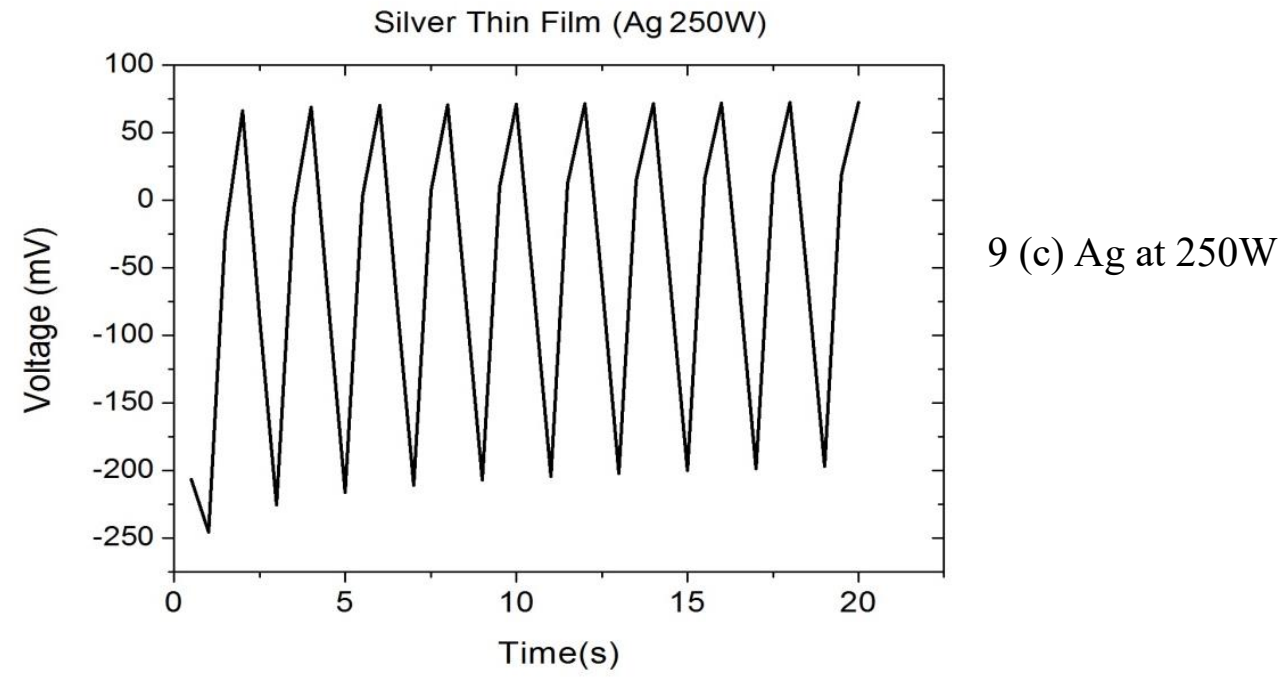

Figure 9. Charge-discharge of Ag thin films. 

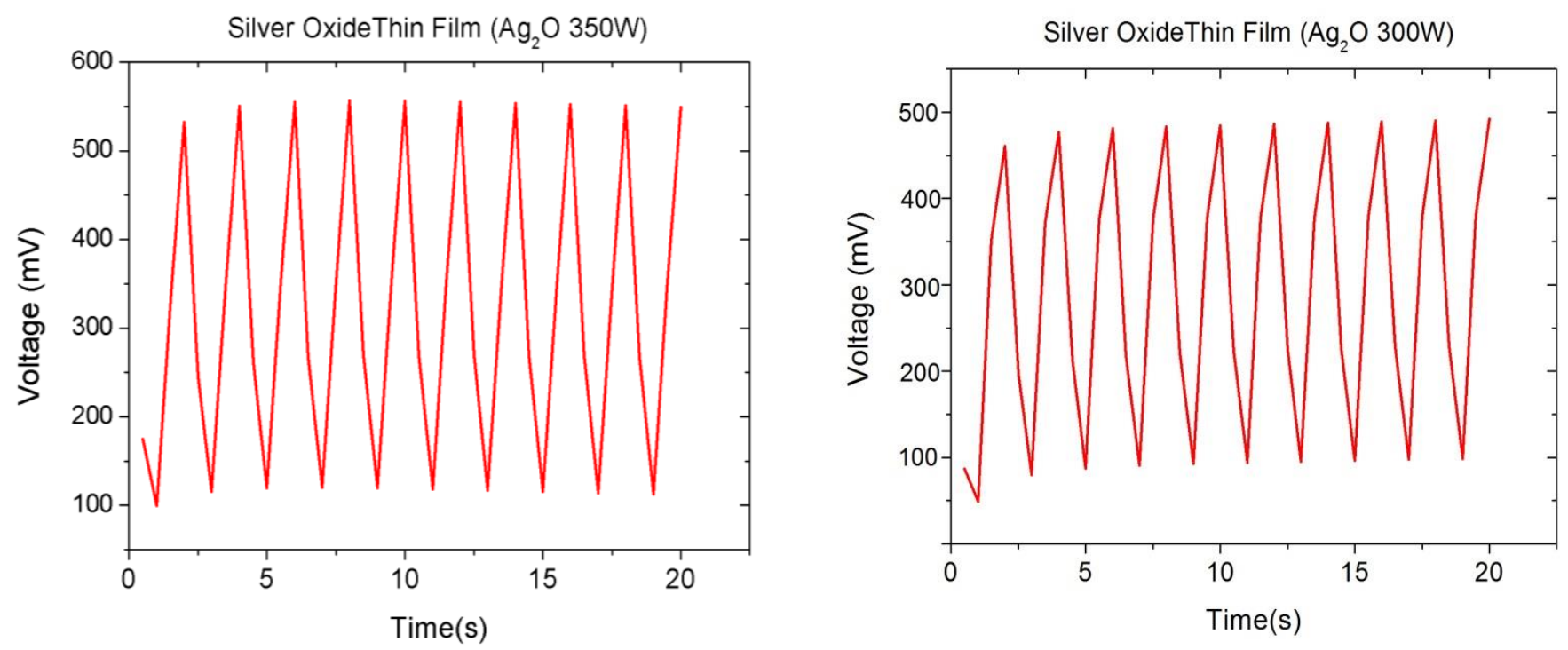

10 (a) $\mathrm{Ag}_{2} \mathrm{O}$ at $350 \mathrm{~W}$

10 (b) $\mathrm{Ag}_{2} \mathrm{O}$ at $300 \mathrm{~W}$

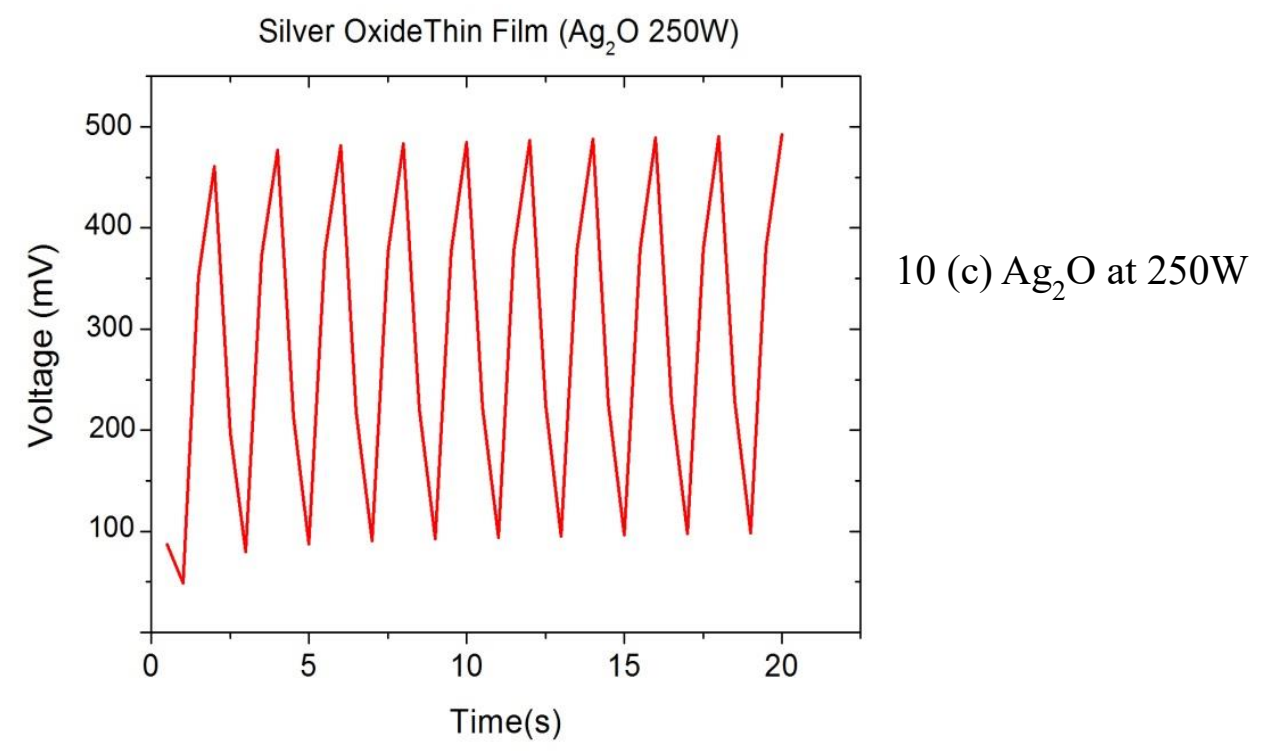

Figure 10. Charge-discharge of $\mathrm{Ag}_{2} \mathrm{O}$ thin films. 


\section{CONCLUSIONS:}

Radio frequency sputtering techniques have been used to produce suitable and columnar microstructure silver and silver oxide thin films for pesudocapacitor application. The electrolyte penetration was supported by combining goniometer and tensiometer analysis, which revealed the hydrophilic nature of silver and silver oxide thin films, with smaller receding contact angle values, indicating electrolyte wetting/penetration into the thin films. The contact angles decreased with increase in pore structure and sputtering power, with tensiometry providing the relationship between the advancing, receding, contact hysteresis and wettability.

Furthermore, results from cyclic voltammetry reveal that silver oxide thin film possess a specific capacitance of $275.50 \mathrm{~F} / \mathrm{g}$ at $2 \mathrm{mV} / \mathrm{s}$ compared to $240.52 \mathrm{~F} / \mathrm{g}$ at $2 \mathrm{mV} / \mathrm{s}$ for silver thin film. This makes silver oxide a viable electrode material for supercapacitor application.

Competing interests. We declare we have no competing interests.

Funding. We received no funding for this study. 


\section{REFERENCE}

[1] Andrew Burke, Hengbing Zhao, Research Report -UCD-ITS-RR-15-09 April 2015

[2] Peter J. Hall, Mojitaba Mirzaeian, S. Isobel Fletcher, Energy storage in electrochemical capacitors-designing functional materials to improve performance: Energy Environ Sci 3 (2010) 1238-1251.

[3] M. Winter, R.J. Brodd, What are batteries, fuel cells, and supercapacitors? Chemical Reviews 104 (2004) 4245-4269.

[4] B.E. Conway, Electrochemical Capacitors: Scientific Fundamentals and Technological Applications, Kluwer Academic/Plenum, London, 1999.

[5] C.D. Lokhande, D.P. Dubal, Oh-Shim Joo, Metal oxide thin film based supercapacitors, Current Applied Physics 11 (2011) 255-270.

[6] V.D. Patake, C.D. Lokhande, O.S. Joo, Electrodeposited ruthenium oxide thin films for supercapacitor: effect of surface treatments, Applied Surface Science 255 (2009) 4192-4196.

[7] S.G. Kandalkar, C.D. Lokhande, R.S. Mane, S.H. Han, A non-thermal chemical synthesis of hydrophilic and amorphous cobalt oxide films for supercapacitor application, Applied Surface Science 253 (2007) 3952-3956. 
[8] U.M. Patil, R.R. Salunkhe, K.V. Gurav, C.D. Lokhande, Chemically deposited nanocrystalline $\mathrm{NiO}$ thin films for supercapacitor application, Applied Surface Science 255 (2008) 2603-2607.

[9] Kalakodimi Rajendra Prasad, Kazumichi Koga, Norio Miura, Electrochemical deposition of nanostructured indium oxide: high-performance electrode material for redox supercapacitors, Chemistry of Materials 16 (2004) 1845-1847.

[10] Pengfei Wang, Hui Liu, Yuxing Xu, Yunfa Chen, Supported ultrafine ruthenium oxides with specific capacitance up to $1099 \mathrm{~F} \mathrm{~g}^{-1}$ for a supercapacitor, Electrochimica Acta 194 (2016) 211-218.

[11] Dipali S. Patil, S.A. Pawar, R.S. Devan, S.S. Mali, Polyaniline based electrodes for electrochemical supercapacitor: Synergistic effect of silver, activated carbon and polyaniline, Journal of Electroanalytical Chemistry 724 (2014) 21-28.

[12] Pramod K. Kalambate, Riyaz A. Dar, Shashi P. Karna, Ashwini K. Srivastava, High performance supercapacitor based on graphene-silver nanoparticles-polypyrrole nanocomposite coated on glassy carbon electrode, Journal of Power Sources 276 (2015) 262-270.

[13] Mojtaba Mirzaeian, Abraham Ogwu, Hassan Fathinejad Jirandehi, Saule Aidarova, Surface characteristics of silver oxide thin film electrodes for supercapacitor applications, Colloids and Surfaces A: Physicochem. Eng. Aspects 519 (2017) 223-230. 
[14] Naidu Dhanpal Jayram, D. Aishwarya, S. Sonia, D. Mangalaraj, Analysis on superhydrophobic silver decorated copper Oxide nanostructured thin films for SERS studies, Journal of Colloid and Interface Science 477 (2016) 209-219.

[15] R. Todorov, V. Lozanova, P. Knotek, E. Černošková, Microstructure and ellipsometric modelling of the optical properties of very thin silver films for application in plasmonics, Thin Solid Films 628 (2017) 22-30.

[16] Deepak Sahu, Niladri Sarkar, Gyanaranjan Sahoo, Priyaranjan Mohapatra, Nano silver imprinted polyvinyl alcohol nanocomposite thin films for $\mathrm{Hg} 2+$ sensor, Sensors and Actuators B 246 (2017) 96-107.

[17] Zhengyan Chen, Congling Li, Yangyang Ni, Fantao Kong, TCNQ-induced insitu electrochemical deposition for the synthesis of silver nanodendrites as efficient bifunctional electrocatalysts, Electrochimica Acta 239 (2017) 45-55.

[18] R. Dimitrijević, O. Cvetković, Z. Miodragović, M. Simić, SEM/EDX and XRD characterization of silver nanocrystalline thin film prepared from organometallic solution precursor, J. Min. Metall. Sect. B-Metall. 49 (2013) 91-95.

[19] Rita Rebelo, N.K. Manninen, Luísa Fialho, Mariana Henriques, Morphology and oxygen incorporation effect on antimicrobial activity of silver thin films, Applied Surface Science 371 (2016) 1-8.

[20] Kalyanaraman Kalpana, Vaithilingam Selvaraj, A novel approach for the synthesis of highly active $\mathrm{ZnO} / \mathrm{TiO}_{2} / \mathrm{Ag}_{2} \mathrm{O}$ nanocomposite and it's photocatalytic applications, Ceramics International 41 (2015) 9671-9679. 
[21] Hamid Entezar Mehdi. M.R. Hantehzadeh, Shahoo Valedbagi, physical properties of silver oxide thin film prepared by dc magnetron sputtering: effect of oxygen partial pressure during growth, J. Fusion Energy 32 (2013) 28-33.

[22] M.F Al-Kuhaili, Characterization of thin films produced by thermal evaporation of silver oxide, J. Phys. D: Appl. Phys. 40 (2007) 2847-2853.

[23] P. Narayana Reddy, M. Hari Prasad Reddy, J. F. Pierson, S. Uthanna, Characterization of silver oxide thin films formed by reactive RF sputtering at different substrate temperature, ISRN Optics Volume 2014, Article ID 684317, 7 pages.

[24] Geoffrey I. N. Waterhouse, Graham A. Bowmaker, James B. Metson, The thermal decomposition of Silver (I, III) oxide: A combined XRD, FTIR and Raman spectroscopic study, Phys. Chem. Chem. Phys 3 (2001) 3838-3845.

[25] Myat Htut, Myo Lwin, Pho Kaung, Sein Htoon, Infrared Spectroscopic Study on the Structure of Ag2O.B2O3 Glasses, Jour. Myam Acad. Arts \& Sc. 2006 Vol. IV. No. 2.

[26] M. Rafiq H. Siddiqui, S.F. Adil, M.E. Assal, Roushown Ali, Synthesis and Characterization of Silver Oxide and Silver Chloride Nanoparticles with High Thermal Stability, Asian Journal of Chemistry 25 (2013) 3405-3409.

[27] F.A Cotton et al, Advanced Inorganic Chemistry 3rd ed. (Wiley Interscience, New York 1972 pp1050. 
[28] Tiffany C. Kaspar, Tim Droubay, Scott A. Chambers, Paul S. Bagus, Spectroscopic evidence for Ag (III) in highly oxidized silver films by X-ray photoelectron spectroscopy, J. Phys. Chem. C 114 (2010) 21562-21571.

[29] Xiao-Yong Gao, Song-You Wang, Jing Li, Yu-Xiang Zheng, Study of structure and optical properties of silver oxide films by ellipsometry, XRD and XPS methods, Thin Solid Films 455 -456 (2004) 438-442.

[30] Weifeng Wei, Xuhui Mao, Luis A. Ortiz and Donald R. Sadoway, Oriented silver oxide nanostructures synthesized through a template-free electrochemical route, Journal of material chemistry 21 (2010) 432-438.

[31] F. Paladini, R.A. Picca, M.C. Sportelli, N. Cioffi, Surface chemical and biological characterization of flax fabrics modified with silver nanoparticles for biomedical applications, Materials Science and Engineering C 52 (2015) 1-10.

[32] Ana Maria Ferraria, Ana Patrícia Carapeto, Ana Maria Botelho do Rego, X-ray photoelectron spectroscopy: Silver salts revisited, Vacuum 86 (2012) 1988-1991.

[33] Nawal Boukmouche, Noureddine Azzouz, Lamia Bouchama, Anne Lise Daltin, Supercapacitance of $\mathrm{MnO} 2$ films prepared by pneumatics spray method, Materials Science in Semiconductor Processing 27 (2014) 233-239.

[34] Li-Xia Yanga, Ying-Jie Zhu, Hua Tong, Zhen-Hua Liang, Hydrothermal synthesis of nickel hydroxide nanostructures in mixed solvents of water and alcohol, Journal of Solid State Chemistry 180 (2007) 2095-2101. 
[35] W.G. Pell, B.E. Conway, Voltammetry at a de Levie brush electrode as a model for electrochemical supercapacitor behaviour, Journal of Electroanalytical Chemistry 500 (2001) 121-133

[36] J.Wei, N Nagarajan, I. Zhitomirsky, Manganese oxide films for electrochemical supercapacitors, Journal of Materials Processing Technology 186 (2007) 356-361.

[37] P. Staiti, F. Lufrano, Study and optimization of Manganese oxide-based electrodes for electrochemical supercapacitors, journal of power sources 187 (2009) 284-289.

[38] Yong Zhang, Guang-yin Li, Yan Lv, Li-zhen Wang, Electrochemical investigation of $\mathrm{MnO} 2$ electrode material for supercapacitors, international journal of hydrogen energy 36 (2011) $11760-11766$.

[39] J. Keraudy, J. García Molleja, A. Ferrec, B. Corraze, Structural, morphological and electrical properties of nickel oxide thin films deposited by reactive sputtering, Applied Surface Science 357 (2015) 838-844.

[40] Youyi Sun, Wenhui Zhang, Diansen Lib, Li Gao, Direct formation of porous $\mathrm{MnO} 2 / \mathrm{Ni}$ composite foam applied for high-performance supercapacitors at mild conditions, Electrochimica Acta 178 (2015) 823-828.

[41] Ma Jiao-Min, Liang Yan, Gao Xiao-Yong, Zhang Zeng-Yuan, Effect of substrate temperature on microstructure and optical properties of single-phased Ag2O film deposited by using radio-frequency reactive magnetron sputtering method, Chin. Phys. B 20 (2011) 056102. 
[42] A.I. Inamdar, Young Sam Kim, S.M. Pawar, J.H. Kim, Chemically grown, porous, nickel oxide thin-film for electrochemical supercapacitors, Journal of Power Sources 196 (2011) 2393-2397.

[43] C.G. Jothi Prakash, C. Clement Raj, R. Prasanth, Fabrication of zero contact angle ultra-super hydrophilic surfaces, Journal of Colloid and Interface Science 496 (2017) 300-310

[44] Xingxun Li, Xianfeng Fan, Stefano Brandani, Difference in pore contact angle and the contact angle measured on a flat surface and in an open space, Chemical Engineering Science 117 (2014) 137-145

[45] D.P. Dubal, D.S. Dhawale, R.R. Salunkhe, C.D. Lokhande, Fabrication of copper oxide multilayer nanosheets for supercapacitor application, Journal of Alloys and Compounds 492 (2010) 26-30.

[46] Oluf Bøckman, Terje Østvold, George A. Voyiatzis, George N. Papatheodorou, Raman spectroscopy of cemented cobalt on zinc substrates, Hydrometallurgy 55 (2000) 93-105.

[47] R. Wenzel, Resistance of solid surfaces to wetting by water, Ind. Eng. Chem. 28 (1936) 988-994.

[48] A.B.D. Cassie, S. Baxter, Wettability of porous surfaces, Trans. Faraday Soc. 40 (1944) 546-551. 
[49] Sara L. Schellbach, Sergio N. Monteiro, Jaroslaw W. Drelich, A novel method for contact angle measurements on natural fibers, Materials Letters 164 (2016) 599_ 604.

[50] R. Belibel, C. Barbaud, L. Mora, Dynamic contact angle cycling homogenizes heterogeneous surfaces, Materials Science and Engineering C 69 (2016) 1192-1200.

[51] C.W. Extrand, Uncertainty in contact angle estimates from Wilhelmy tensiometer, Journal of Adhesive Science and Technology 29 (2015) 2515-2520.

[52] Recep Yuksel, Sahin Coskun, Yunus Eren Kalay, Flexible, silver nanowire network nickel hydroxide core-shell electrodes for supercapacitors: J. Power Sources 328 (2016) 167-173.

[53] Recep Yuksela, Ece Alpuganc, Husnu Emrah Unalana, Coaxial silver nanowire/polypyrrole nanocomposite supercapacitors: Organic Electronics 52 (2018) $272-280$

[54] Junyan Liu, Tinghui Jiang, Feng Duan, Electrophoresis deposition of flexible and transparent silver nanowire/graphene composite film and its electrochemical properties: Journal of Alloys and Compounds 745 (2018) 370-377.

[55] Kyle T. Braam, Steven K. Volkman, Vivek Subramanian, Characterization and optimization of a printed, primary silver-zinc battery: Journal of Power Sources 199 (2012) 367-372. 


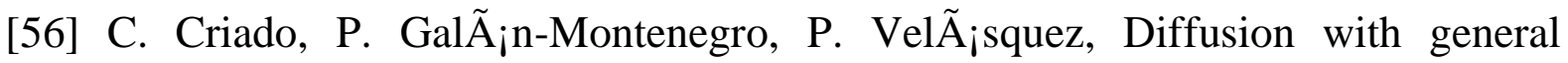
boundary conditions in electrochemical systems: Journal of Electroanalytical Chemistry 488 (2000) 59-63.

[57] Liza Rassaei, Assembly and Characterization of Nanomaterials into Thin Film Electroanalysis, 3rd July 2008.

[58] Y.L Yin, J.Y. Park, Electrochemical investigation of Copper/nickel oxide composites for supercapacitor applications, international journal of hydrogen energy 39 (2014) $16562-16568$

[59] Farrukh Iqbal Dar, Kevin Radakishna Moonooswamy, Mohammed Es-Souni, Morphology and property control of $\mathrm{NiO}$ nanostructures for supercapacitor applications, Nanoscale Research Letters 8 (2013), 363.

[60] Shuaishuai Zhu, Yuming Dai, Wei Huang, Chuanxiang Zhang, In situ preparation of $\mathrm{NiO}$ nanoflakes on $\mathrm{Ni}$ foams for high performance supercapacitors, Materials Letters 161 (2015) 731-734.

[61] Abbas-Ali Malek Barmi, Mustafa Aghazadeh, Behzad Arhami, Hamid Mohammad Shiri, Porous cobalt hydroxide nanosheets with excellent supercapacitive behaviour, Chemical Physics Letters 541 (2012) 65-69.

[62] X. Zhang, S. Stewart, D.W. Shoesmith, J.C. Wren, Interaction of Aqueous Iodine Species with $\mathrm{Ag}_{2} \mathrm{O} / \mathrm{Ag}$ surfaces, Journal of The Electrochemical Society 154 (4) F70F76 (2007). 
[63] Jalal Ghilane, Fu-Ren F. Fan, Allen J. Bard, Facile Electrochemical characterization of core/shell Nanoparticles, $\mathrm{Ag}$ core $/ \mathrm{Ag}_{2} \mathrm{O}$ shell structure. Nanoletters 7 (2007) 1406-1412.

[64] J. Turner, Electrolytic studies on the system $\mathrm{Ag} / \mathrm{Ag}_{2} \mathrm{O} / \mathrm{AgO}$ in alkaline chloride solutions, journal of applied electrochemistry 7 (1977) 369-378.

[65] Masato Tominaga, Toshihiro Shimazoe, Makoto Nagashima, Hideaki Kusuda, Electrocatalytic oxidation of glucose at gold--silver alloy, silver and gold nanoparticles in an alkaline solution, Journal of Electroanalytical Chemistry 590 (2006) 37-46.

[66] Sheela Berchmans, Amay J. Bandodkar, Wenzhao Jia, Julian Ramírez, An Epidermal alkaline rechargeable $\mathrm{Ag}-\mathrm{Zn}$ printable tattoo battery for wearable electronic, J. Mater. Chem. A 2 (2014), 15788-15795.

[67] Nilesh R. Chodankar, Deepak P. Dubal, Girish S. Gund, Chandrakant D. Lokhande, Flexible all-solid-state $\mathrm{MnO}_{2}$ thin films based symmetric supercapacitors" Electrochimica Acta 165 (2015) 338-347.

[68] S. Khamlich, T. Khamliche, M.S. Dhlamini, M. Khenfouch, Rapid microwaveassisted growth of silver nanoparticles on 3D graphene networks for supercapacitor application, Journal of Colloid and Interface Science 493 (2017) 130-137.

[69] A.V. Radhamani, M.S. Ramachandra Rao, Tunable supercapacitance of electrospun $\mathrm{Mn}_{3} \mathrm{O}_{4}$ beaded chains via charge- discharge cycling and control parameters, Applied Surface Science 403 (2017) 601-611. 
[70] A.D. Jagadale, V.S. Kumbhar, D.S. Dhawale, C.D. Lokhande, Performance evaluation of symmetric supercapacitor based on cobalt hydroxide $\left[\mathrm{Co}(\mathrm{OH})_{2}\right]$ thin film electrodes, Electrochimica Acta 98 (2013) 32-38. 


\section{HIGHLIGHTS}

- Surface wettability of prepared $\mathrm{Ag}$ and $\mathrm{Ag}_{2} \mathrm{O}$ thin films are hydrophilic in nature.

- Tensiometer analysis reveal electrolyte penetration and contact angle hysteresis.

- $\mathrm{Ag}$ and $\mathrm{Ag}_{2} \mathrm{O}$ Microstructure are deposition power dependent.

- $\mathrm{CV}$ results showed compact anodic and cathodic peaks with $275.50 \mathrm{~F} / \mathrm{g}$ capacitance. 